\title{
Communicating the Public Interest: A Case Study Of SaskTel
}

\section{DEVIN DUBOIS}

\section{Prof. Joy Cohnstaedt}

The Major Research Paper is submitted in partial fulfillment of the requirements for the degree of Master of Arts

\author{
Joint Graduate Programme in Communication \& Culture \\ Ryerson University - York University \\ Toronto, Ontario, Canada
}

September 24, 2004 


\section{CONTENTS}

1. Introduction 1

2. Communicating the Past 3

a. Telegraph to Telephone 6

b. The Railway Delivers 7

c. Cutlure of The West 8

d. Communication Catch-Up 10

e. The System Takes Shape 14

f. The Crown Acquires its Jewel 16

3. SaskTel the Common Carrier 21

a. Pioneering the Digital Revolution 25

b. Preparing For the Fight-Looming Competition 27

4. Communication (R)Evolution 30

a. Uncertain State of the Industry 31

b. Crown Jewel of Public Enemy? 36

c. Small Fish, Big Pond 42

d. The Price of Competition 47

e. Regulatory Roots of Competition $\quad 50$

f. The Never Ending (Policy) Story 55

5. Techno-Nationalism, The Culture of Communication 58

a. Calling Up Saskatchewan Culture $\quad 60$

6. Defining the Public Interest 64

7. SaskTel, The Cultural Carrier 66

8. Conclusion 69

Appendices

a. Communications Timeline for Saskatchewan

b. Saskatchewan Government Telephone System, 1920

Works Cited 


\begin{abstract}
Saskatchewan presents a worthy study of the public interest in communication distribution policy, as it was the last province in which telecommunications became federally regulated; it is the last province in which the incumbent communication carrier, SaskTel, is fully owned by the provincial government; and it is a geographically large province with a relatively small population-many of whom still live in rural communities. Since its inception, the provincial government has worked to ensure that its sparsely distributed residents have access to the best communication services possible through the crown-owred SaskTel (formerly Saskatchewan Government Telephones). However, what was once a provincially owned and regulated monopoly has now been subject to federal regulation which favours competition in all sectors of the communication industry. The federal government adopted competition in the name of public interest, yet little has been done to assess the effectiveness of this claim. The current climate of uncertainty regarding new communication technologies, federal regulation, and the tide of provincial politics, have spoiled what was once an effective path for SaskTel and Saskatchewan citizens. It is clear that SaskTel's ability to meet its public policy goals is now threatened by the limitations of competition and federal regulation.
\end{abstract}


"Personal interest always wears the disguise of public purpose, and no one is more easily persuaded of the validity of righteousness of a public cause than persons who stand to gain personally therefrom."

\section{-John Kenneth Garlbraith}

\section{INTRODUCTION}

Looking out from my Saskatchewan farmhouse, I see nothing but barren plains spotted by a small handful of grain elevators standing tall on the horizon and a small town whose borders are distinct and slight against the massive backdrop of land and sky. Like the thread which binds together a garment, the railroad ties together the elevators, the town and the surrounding fields of grains, oilseeds, legumes and the odd remaining farmyard. Everything within that picture exists because of the railway. The railway provided both the basic infrastructure for economic development and the means of delivering settlers to the barren prairie landscape. Although the prairie population is becoming more urban, the economy of Saskatchewan is still primarily based on the extraction of natural resources through mining, agriculture and forestry - the very industries the railway was built to encourage. However, the railways and the largest provincial highway network in Canada are not all that enable the Saskatchewan economy and bind its people to the land. The 'information highway', in all its forms, is integral to the economic and cultural maintenance of Saskatchewan.

Saskatchewan presents a worthy study of the public interest in communication distribution policy, as it was the last province in which telecommunications became federally regulated; it is the last province in which the incumbent communication carrier, 
SaskTel, is fully owned by the provincial government; and it is a geographically large province with a relatively small population-many of whom still live in rural communities. Since its inception, the provincial government has worked to ensure that its sparsely distributed residents have access to the best communication services possible through the crown-owned SaskTel (formerly Saskatchewan Government Telephones). However, what was once a provincially owned and regulated monopoly has now been subject to federal regulation which favours competition in all sectors of the communication industry. The federal government adopted competition in the name of public interest, yet little has been done to assess the effectiveness of this claim. The current climate of uncertainty regarding new communication technologies, federal regulation, and the tide of provincial politics, have spoiled what was once an effective path for SaskTel and Saskatchewan citizens. It is clear that SaskTel's ability to meet its public policy goals is now threatened by the limitations of competition and federal regulation. In fact, the experience of this composition, itself, demonstrates the problem.

A portion of this paper was composed within a Saskatchewan farmhouse roughly $120 \mathrm{~km}$ west of Saskatoon. The house was built only four years ago just $4 \mathrm{~km}$ outside of a farming community of 2800 people, which serves as an agricultural service centre for the surrounding area. The farmhouse has the convenience of digital satellite television through Star Choice; two phone lines through SaskTel, and a private VHF radio channel for farm communication. The area is also now served by digital cellular phone service from SaskTel. At first glance, the farm seems well connected to the world at large. However, it is still lacking access to the 'on ramp' of the Information Highwaybroadband Internet. Although both SaskTel and its lone competitor (in Internet 
provision) in the region offer broadband Internet within the town, only $4 \mathrm{~km}$ away, the economics prevent the service from spreading outward to the surrounding farms. While SaskTel continues to offer more innovative communication services like 'higher-speed' Internet, digital television and remote security surveillance in the larger centres, they fail to provide what is now basic communication infrastructure to many rural clients.

SaskTel used to focus on eliminating this kind of 'technological disparity' throughout the province. However, federal regulation has forced SaskTel into a competitive environment where public policy goals are now mitigated by economic considerations. As a result of this, many Saskatchewan citizens who do not live in 'viable markets' have been left behind in the wake of the Communication Age.

\section{COMMUNICATING THE PAST}

On March 25, 1908, a report filed with the Saskatchewan Department of Railways instigated the public acquisition and expansion of telephone service that remains today. The telephone marks the arrival of the first public utility in the province, preceding electricity and natural gas, while it also marks the expansion of the connective networks in the province which included railways, roads and the telegraph. As with the telegraph, the telephone was originally grouped with railways for administrative purposes-they were treated as an expansion of the connective network. It was much later, during the mass introduction of electricity that the view of telephones as a utility evolved. Either way, it is certainly fair to categorize telephones as part of the economic, and therefore, social infrastructure. In fact, the telegraph, the precursor of the telephone, preceded the railway on most parts of the prairies, paving the way for the arrival of government and 
settlers. A brief history of telephone development amidst the evolution of the province as a whole will demonstrate its infrastructural importance while it will highlight the political and social ideas that fostered government involvement in the development the Saskatchewan economy.

The telegraph was the first industrial connective technology to grace the windswept prairie landscape. It preceded the railway and made short work of messages that were previously carried by riders. Although fur traders, missionaries and explorers were the original bastions of the Dominion in the vast Northwest, the government presence grew rapidly as the notion to populate and develop the land progressed. In advance of the railway and agricultural settlement, a limited telegraph system tied together the small settlements which included mostly trading posts and North West Mounted Police (NWMP) forts. A telegraph line was completed in 1876 that ran from Livingston, Manitoba to the current Alberta border on a northwesterly route roughly following the Saskatchewan River toward Edmonton. This line preceded the railway by nearly ten years. The presence of the telegraph was paramount to the organization and preparation of the vast Northwest Territories for agricultural settlers. J. S. Macdonald writes in his personal history of the telegraph that:

Of the factors instrumental in changing that portion of the North West Territories which now comprises the Provinces of Saskatchewan and Alberta from a vast wilderness to the greatest wheat exporting district on the globe, undoubtedly the Canadian Pacific Railway ranks first. But the country had to be prepared for the railroad and for settlement. Here the North-West Mounted Police takes first place. Second only in importance was the building of a telegraph line by the Dominion Government from Winnipeg to Edmonton, a distance of almost 1,000 miles by the route taken, and the establishment of telegraph offices at strategical points along the way. (15) 
The link between government, order and communication was most clearly demonstrated by the role of the telegraph in the Northwest Rebellion of 1885 . Macdonald recalls that:

Without it the trouble could not have possibly been brought to an end during that year... Without the wire, the condition of affairs throughout the whole northern country would have been absolutely unknown outside, for the Police were too few and too much occupied to establish a patrol to the newly-built railway to the south.... Police officers, Indian agents and missionaries did splendid work in pacifying and persuading the Indians of many reserves from rising, but lacking the information they received by way of the telegraph, their efforts would have availed but little. (35)

The telegraph was not only a means of communication amongst those already in the territory, but it was a tool of central planning and connection with the federal government.

The introduction of communication technologies was driven purely by the Canadian government and their desire to establish settlement. The Indian and Métis populations neither required nor desired any technologically advanced communication system. The telegraph and, eventually, the railway, can be considered the extensions of the state that quelled the last vestiges of resistance by the aboriginal population in Saskatchewan. Macdonald's assertions clearly support this notion, while he also states in his account of the Rebellion that the telegraph line was cut on only a couple occasions (36) - a sign that, perhaps, the rebels did not fully understand the logistical value of a rapid communication system. Communication technology heralded the arrival of the Canadian state and the coming of settlers. In this way, communication technology is synonymous with Canadian identity in the West-an idea we shall return to in this analysis.

As the railway entered the province, the telegraph became a tandem technology that operated and evolved in conjunction with the expansion of the rail system. While the 
original telegraph line had been operated by the Great Northwest Telegraph Company, the federal government took control of the line in 1881 (Macdonald). Subsequent telegraph expansion became the activity of the railway companies who laid line along their newly constructed routes. Thus, the railways and telegraphs became fused in their treatment and administration by both the federal and provincial governments. The parallel network of railways and telegraphs became the skeleton and nervous system-the backbone - of the prairie economy, administration and socialization.

\section{Telegraph to Telephone-Regulation Takes Shape}

Newspapers on the prairies relied almost exclusively on telegraph transmissions as their source of news from abroad. Eventually, rifts developed over the transmission rates being charged. The Canadian Pacific Telegraph (CPT), because it owned the most extensive network, including some bottleneck facilities, was the worst perpetrator of exorbitant transmission fees. In this instance, the telegraph lines had become the vertically integrated carriers and producers of information, and they were clearly abusing that design. In 1910, the federal Board of Railway Governors ruled that CPT prices were discriminatory and, thus, illegal. This marked the end of vertical integration for the telegraph carriers and the beginning of a keen federal interest in regulating communication flows (Babe 1990, 54-62). Thus far, it appears that the communication technologies, the railroad and the telegraph, were mechanisms of capturing the west for the sake of the east and that all flows of traffic and communication suited the economic and political goals of the east. However, the introduction of the telephone transformed local community as much as it fostered the economy. 
While the design and expansion of the telegraph and railway progressed from the centre outward, maintaining a connection to the single, large, centralized network, the development of the telephone on the prairies was very sporadic and decentralized. Telegraphs connected communities of people with other communities, while telephones initially connected communities of people with each other. In the pivotal 1908 report on telephones by Francis Dagger, it is stated that "...nearly 98 per cent of the communications over any telephone system are local conversations. " Dagger further wrote that “...the business of furnishing a public utility which comprises 98 per cent of local service does not rightly devolve upon a government but is rather one which should be placed in the same class as water, gas, electrical light and power..." (8). Unlike the modern notion that communication technology connects individuals to the broader world, early policy makers in Saskatchewan clearly regarded telephone service as primarily local in nature. As a result, Dagger recommended a system in which long distance connections were developed and maintained by the state, while local networks be developed and maintained by local companies, cooperatives or municipalities. Indeed, that became the model that the provincial Department of Railways, Telegraphs and Telephones chose for the development of the system, as described in the Telephone Acts in 1908.

\section{The Railway Delivers}

The early development of the communication infrastnucture in Saskatchewan follows the same design as the development of most physical infrastructure in the province. The unparalleled wave of immigration that poured across the prairies at the turn of the century had a profound impact on the style of the province's development. Between 1901 and 1906, the population of the province surged from 91279 to 257763 , 
while $86.8 \%$ of that 1906 population was settled in rural areas. The population nearly doubled again by 1911 when it reached 492432 , while over $80 \%$ remained settled in rural areas (Archer 360). In its first decade as a province Saskatchewan experienced a five-fold increase in population! The population of the province continued to increase rapidly until it finally peaked in the late 1930's at close to 950000 people. The vast majority (over $80 \%$ ) of the population remained in rural areas until after the Second World War when there began a shift toward urbanization. To properly understand the rapid impact of population growth, it is helpful to turn to a first-hand impression of prairie expansion. The journals of German journalist Willhelm Cohnstaedt recount his travels across the Canadian West in 1909. He recorded a general atmosphere of optimism, anticipation for the future and unbridled growth in some locals. Of Winnipeg, the 'Gateway to the West' and the starting point for his journey, Cohnstaedt writes:

Here, the first historic chapters of a new national economy emerge before our very eyes. At this point the city is not yet an entity as such, but only an outgrowth of agriculture. It belongs to its means of production in the same way as the plough, the threshing-machine and the dairy... just like the typical American city, Winnipeg considers itself primarily a building site and only secondarily a built-up area. It lives entirely in the future... One does not build for today's city of 125,000 inhabitants, nor even for the surely foreseeable Canadian Minneapolis of 300,000, but for the projected city of a million, the Canadian Chicago. (2-3)

As noted by Cohnstaedt, the estimated population of Winnipeg was 125,000 in 1909, up from 42,300 in 1901 according to his observations. Also important are the recognition of a "new national economy" and the ties of the Canadian West to the American West. The current status of prairie economics and cultural identification remain closely tied to these historic foundations. 


\section{Culture of The West}

If the Canadian government embarked on the creation of the CPR and the National Policy to assert their economic and political sovereignty throughout the entire prairies, they relied heavily on settlers from the US to fill the population gap-they recruited American settlers to prevent American annexation. Cohnstaedt writes:

The fact that free land in the United States has more or less been divided up is considered to be the strongest reason for the enormous increase in immigration here... During the past year 59,000 of the immigrants into Canada were from the United States - as compared to 52,000 from Great Britain and only 34,000 from all other countries... In Canada, the government and the people consider the Americans to be by far the most welcome settlers. (9)

Cohnnstaedt suggests strongly throughout his journals that the settled Canadians highly favoured settlers from the American mid-west who were accustom to the climatic and soil conditions. Cohnstaedt does mention, though, that most 'American' settlers he encountered had some measure of Germanic roots. John Archer's research supports Cohnstaedt's observation that Americans were favoured settlers. And Archer, like Cohnstaedt, states that even 'American' settlers were not necessarily American-born. He writes:

American immigration had a marked impact on western Canada. Year after year the national group making the most homestead entries was the Americans... It should be noted that immigration from the United States had an international character. There were Hutterites, Dunkards [German-American Baptists] and Mennonites seeking further economic opportunities. The most highly prized immigrants were those born in the United States, those who had been in the United States long enough to have been assimilated into the culture... These had the expertise, capital and the common language... and became the main target for the immigration branch... (140)

It can be easily understood how the cultural and economic foundations of the Canadian prairies approximate, and even mimic, the design of the American Midwest. This fact will be revisited when this analysis addresses the impact of communication in Canadian 
'nation building' efforts. In many ways, the cultural foundations of the American West are the cultural foundations of the Canadian West. The flood of immigration that spilled onto the prairies at the turn of the century came largely by way of Chicago and Minneapolis.

\section{Communication Catch-Up-Developing the Infrastructure}

The rapid, rural population explosion largely explains the nature of early infrastructural development in the province of Saskatchewan. The newly formed province needed to respond immediately to both the economic and social needs of many sparsely settled pioneers. Railways, roads, schools, telegraphs and telephones were all in short supply for the vast rural population, yet immigrants continued to flow to the fringes of the prairies and into the northern parkland beyond the ends of the railway. Although railways formed the original paths to settlements, they followed what were suspected to be fertile tracts of land. The swell of immigration at the turn of the century eventually pushed beyond the ends of the existing ends of the railway branch lines at the time. The Saskatchewan government was playing catch-up the minute they assumed power over the burgeoning prairie province in 1905. It is a combination of this population surge, the settlement design of government- the Dominion Land Survey and the Dominion Lands Act of 1872 -and the agricultural economy that produced specific infrastructural needs that could only be met through specific government solutions. The Dominion Lands Act required settlers to live on their homesteads and cultivate the land, creating a landscape dotted with isolated, individual farms. Thus, isolation and separation-both economically and socially — became a primary concern of the settlers and the provincial government. 
As the prairie population exploded, the resources of the new provincial government and the investment by industry failed to keep pace with needed infrastructural expansions. The public purse could ill afford to develop railway branch lines, telephone lines and roads throughout the rural areas simultaneously. However, when the province was founded in 1905, the British North America Act granted the province the power to borrow money on its own credit. Thus, the government adopted the standard approach of encouraging local municipalities and organizations to develop the necessary infrastructure in their regions through grants, loans and loan guarantees. The municipalities were originally "territorial units" of 9 townships each, as developed by the Walter Scott government in 1909 (Archer 153). The local units had the option of voting to become municipalities to obtain more power from the provincial government. Most localities eventually became municipalities and, thus, became integral players in Saskatchewan's development.

Because the provincial government could scarcely afford to meet all of the infrastructural demands, they delegated many responsibilities to the newly formed Rural Municipalities. This was certainly true for the development of roads, telephones and electricity. Although responsibility for development was localized, the provincial government exercised a strong hand in designing and shaping the broader systems of infrastructure. Before settlers arrived and before the province was formed, the land was already surveyed on a mile-by-mile grid system which granted land for schools, determined where road allowances would pass and marked the clear division of townships as administrative units. Thus, a large measure of central design was employed before the provincial government even existed, while the construction and maintenance 
of most infrastructures was left to the various localities. Although this provided clear sovereignty over their road systems to the municipalities, it became clear that some measure of provincial planning was necessary. A. J. McPherson, Superintendent of Highways reported the following concern in his 1910 report to government:

In driving over different parts of the country one sees the results of more or less conflict in authority not only between adjoining local districts but also between councilors for different townships in the same district and also between the Government and the local authorities. This is evidenced by a main road lying between districts being neglected while less important roads receive attention and there seems to be a tendency in some districts for the local authorities to neglect any road on which the Government has spent money and to divert their funds to less important places... (28)

As a result of this situation, McPherson recommended that the province dedicate its funding to the maintenance of main roads that generally served to connect the municipalities. Thus, the current network of provincial highways and municipally maintained grid roads was born. In 1919, the federal government stepped into the fray to ensure the orderly development of a coast-to-coast highway system through funding to the provinces under the Canada Highways Act. This became only one of the many communicative systems over which the federal government wished to retain some influence.

The initially slow growth of railway, which both ferried the masses of settlers across the prairies to their new settlements and shuttled the prairie commodities back to the eastern market, was of primary concern to both government and settlers. In his 1913 report to the government on that state of transportation in the province, J. A. Calder stated that:

The question of railroad development continues to be one of the most serious of immediate problems confronting the province especially in view of the rapid settlement of our territory which continues. Boundless wastes and districts 
formerly inhabited by a sparse population of struggling pioneers continue to grow into thriving and prosperous communities riper for, and demanding, means of railroad transit. The population has grown from about 250,000 in 1905, at which time the province was created, to over 490,000 in 1911, when the last census was taken. (5)

In order to expedite the construction of railways the provincial government, in 1913 , began to guarantee the bonds of companies who agreed to build branch lines. Although the expansion of railways was largely an economic concern, Calder made mention of the social implications as well. In 1914 he wrote:

Increased rail transportation is necessary also to unite the different settlements which are now scattered and should be consolidated by providing means for social as well as commercial intercourse. The effect of railway development in the past touching the prosperity and well-being of the people has been perfectly obvious and appreciable although not capable of being expressed in language of figures, and from this viewpoint it is earnestly to be desired that it will be possible for the era of railway expansion to contimue... (7)

However, the construction of railways was only half the battle. In Saskatchewan's early development, the province was constantly calling on the federal government to improve grain handling capacity and the national grain transportation system, as prairie farmers continuously encountered the lack of capacity for their ever-increasing yields.

[Railway] Cars were supplied freely at first with the least possible delay. Gradually the long haul to the one port of exit absorbed the car supply. Gradually the flow of grain overtook the vessel space and space in the terminal elevators at the head of the lakes. Shipments could not be cleared so freely. Cars could not be returned promptly. Interior elevators filled up and the grain movement came to a standstill, where it remains today. (Calder 1913, 7)

Thus, the province was locked into an unsavory relationship with the federal government and the industry players it supported (namely the CPR and the CNR). The province had developed a vast portion of the transportation infrastructure, which was constructed on a speed and scale that was entirely unrivaled in the country. Yet, it could not escape the ultimate influence of the federal government. 


\section{Telephone System Takes Shape}

The nature of road and railway development in the province is strikingly similar to that of telephone development. In the same way, municipalities and towns developed independent telephone systems to serve their own residents' needs for local communication, while the provincial government eventually intervened to provide longdistance connections. Although the road system was similar in design to the telephone system, and somewhat similar to the railway system, it never received significant attention in the very first years of the Saskatchewan government. However, railways, telegraphs and telephones received immediate attention following the inception of the province through one comprehensive department formed in 1908.

Although it had been dealing with settlement issues since 1905, the government specifically established the Department of Railways, Telegraphs and Telephones in 1908 in order to deal with the growing need for expanded infrastructure. Following the establishment of the Department, the province empowered municipal governments and local cooperatives to develop local telephone systems, while the provincial government began to develop and maintain a long distance network (Statutes of Saskatchewan 1908). The design for the telephone system was a direct result of the report from Francis Dagger which was commissioned the previous year. Dagger, a man of some experience in the development of telephones in Canada, articulated the dangers of granting a monopoly position to one firm to develop both local exchanges and long distance lines. He wrote that "... a company operating both long distance lines and local exchanges in any territory has by reason of its control of the long distance service a virtual monopoly of 
the business to the disadvantage of the general public." (Dagger 1908,2) Dagger acknowledged in his report that although telephone competition had evolved successfully in some parts of the United States, “...it had been necessary to expend millions of dollars in the building of independent long distance lines paralleling those of the "Bell" companies..." (3) However, he indicated that the sparse new population in Saskatchewan could hardly attract the capital necessary to develop and support parallel competing systems. As a result, he recommended that long distance service in Saskatchewan be owned and controlled by the provincial government. However, because of the variable conditions and demographic distributions he suggested that "no system of centralized management can be devised which will adequately meet the needs of a number of different communities..." (7) Thus, local exchanges should be developed and managed by local authorities. The Telephone Acts in 1908 established precisely the system that Dagger recommended, which marked the beginning of the Saskatchewan government's involvement in communication distribution.

Two years after the passage of the Act, the Department of Railways, Telegraphs and Telephones reported that:

The plan adopted to develop a provincial telephone system is working satisfactorily. The system is of a dual nature with government control as the underlying principle. It is comprised of long distance lines and exchanges owned and operated by the government and rural lines erected by co-operation between the government and the people. Through the former means the aim is to establish and maintain an efficient service supported by adequate yet not excessive rates to facilitate the transaction of business within and between clusters of population. $(1910,11)$

Aside from the 'dual nature' of the system, this basic description of the telephone structure in Saskatchewan remained unchanged for the longest time. Rapid expansion and convergence of independent systems, including the Bell plant in 1909, lead to the 
creation of the Department of Telephones in 1913. Thus, the provincial government had clearly established its jurisdiction over the development of a provincial telephone system.

\section{The Crown Acquires its Jewel}

The communication system continued to develop at a steady pace, although supply shortages occurred during the First World War. However, in 1932, the Department of Telephones stepped into the rapidly growing world of radio broadcasting. The annual report of 1933 , it is written that:

...considerable work was undertaken to advertise and develop our broadcasting transmission facilities. Many fine programs were developed and carried to radio stations in the prairie provinces over the facilities of the respective telephone systems. While, due to economic conditions, the commercial use of these facilities did not greatly develop, nevertheless, the high quality of the department's facilities was amply demonstrated to the radio stations and the general public, which should result, when conditions improve, in a considerable volume of this class of business. (5)

This passage provides very important pre-text for this particular analysis, as it signals Saskatchewan's early intention to develop a common, technologically sound communication system. Saskatchewan Government Telephones later became involved with broadcast distribution through the construction of the Trans-Canada microwave network in 1957. However, this paper will address the issue of broadcasting in a later section.

Also to be addressed by a later section of this analysis is the relationship of communication technology to cultural sovereignty. Indeed, it has already been mentioned that expansion of the railway and the settlement of the prairies might have well been a reaction to pressure from the United States. The following excerpt from the 
1934 annual report from the Department of Telephones demonstrates the perceived importance of national sovereignty through communication.

Effective May 1, 1933, the department completed an agreement with the other telephone systems comprising the Trans-Canada Telephone System for the transmitting of trans-oceanic messages by what is known as the all Empire route. This service is from Montreal over the Canadian Marconi Wireless Circuits and the facilities of the British Post Office to points in Great Britain, Northern Ireleand and the Isle of Man. This also includes ship to shore service to the Empress of Britain plying between Quebec and Liverpool, England. Prior to this, all overseas calls from Canadian Points were routed via New York. (6)

At the time, it was perceived to be much more desirable to route calls according to a political allegiance rather than geographical proximity. Although the influence of the federal state remained strong in communication, the control that the Saskatchewan government asserted over their own system only grew over time. The election of Tommy Douglas and the Cooperative Commonwealth Federation Party in 1944 both sealed and amplified the role of the state in both telecommunications and the provincial economy in general.

The CCF preached the establishment of a planned system of social economy for the province in which crown corporations played a key role. Although Douglas is often recognized nationally as the 'founding father' of the publicly funded health system, his hand touched most aspects of the Saskatchewan economy and government bureaucracy. Immediately following the election, the CCF set about enacting a swath of policies, including the re-organization of older crown corporations and the addition of some new ones. This was accomplished through the 1945 legislation entitled An Act respecting the Creation of Corporations for Certain Purposes which permitted the government "to operate any designated industrial or commercial enterprise or undertaking, the operation of which on behalf of the province is deemed advisable for the public good." One of the 
first creations following the legislation was the Government Finance Office (GFO), which was responsible for the financing of all crown corporations. On May $9^{\text {th }}, 1947$, an order-in-council created Saskatchewan Government Telephones (SGT), a crown corporation under the GFO. All authority over the property, operation and development of the provincial telephone system was transferred from the Department of Telephones to SGT. The Department remained in place to provide a regulatory function for the remaining independent operators in the province. The Department was eventually phased-out in the 1990's.

The CCF remained in power until 1964, which provided a continuous stable operating environment for SGT. In 1959, the cabinet provided SGT the authority to make corporate donations to particular community causes. Initial donations were quite small and very select until much later. At the time, SGT maintained an unquestioned monopoly in the province, so there was no need to advertise. Historian Ron Love writes: "In every respect, therefore, SGT's public relations policy differed little from private enterprise then or now, including its desire to keep charitable donations within affordable limits." (198) Thus, the crowns became additional channels for the provincial government to indirectly improve communities throughout the province.

The operation of SGT remained relatively untouched by an interim Liberal government under Ross Thatcher, and was only re-touched by the NDP government of Alan Blakeny in the 1970's. Prior to his political career, Blakeny worked in the Government Finance Office which might account for his approach to the continued consolidation of Saskatchewan crowns. More than anything, the 1970's were 
characterized by rapid technological developments and system improvements. Ron Love characterizes the period as follows:

The growing complexity of network facilities and the introduction of many new customer services certainly reflected the corporation's shifting roles, as the technologies of the future soon occupied the forefront of its activities. The only real difference in government policy toward public enterprise during the Blakeney years was that the approach taken to Crown corporations in general was more disciplined and focused. (203)

It was during the Blakeney years that SGT adopted the trade name SaskTel, and that the GFO became the Crown Investments Corporation. It was also during this period that SaskTel made serious improvements to rural service, introduced cable television—a story that will be further discussed in this paper-and began planning the installation of fibreoptic networks. However, Blakeney and the NDP were unable to fully experience the completion of the fibre network, as the Progressive Conservatives, led by Grant Devine, swept to power in 1982. While Blakeney had resurrected the CCF principals which favoured crown ownership, Devine was a new economist who subscribed to privatization and neo-liberlism.

Although Devine managed to privatize portions of the Crown Investment portfolio, SaskTel and the other 'utility' corporations managed to weather the storm. In fact, Love suggests that SaskTel became recognized as the 'crown jewel' of the Saskatchewan crowns during that period and, therefore, had several advantages over its sister corporations.

First, it had a long history in the province and occupied an important place in both urban and rural Saskatchewan... Devine and his cabinet recognized the widespread popular appeal of the telephone enterprise.... SaskTel's second advantage was its place in the ongoing federal-provincial fight with Ottawa... on the issue of federal jurisdiction over the Canadian telecommunications industry. The approach of the Saskatchewan Tories was "to resist regulation in order to 
maximize managerial flexibility," so as to maintain the cross-subsidization model (for example) of telephone rates." (220)

Love remarks that a third advantage was the demonstrated superiority of SaskTel's system, service and finances over other Canadian carriers. Thus, the maintenance of SaskTel was not only in the interest of the public, but in the interest of the Devine government. Devine did attempt to regulate the pricing of phone service through the Public Utilities Review Commission, which he established to oversee the activities of the crown owned utilities.

The technological sophistication of SaskTel is well documented in SaskTel's 'list of firsts' which it references frequently in reports, speeches and media releases. Although the technological achievements are impressive in themselves, unique to SaskTel was the focus on the delivery of new services to the sparse Saskatchewan population. SaskTel was the first telecommunications company in Canada to complete its rural individual line service program, eliminating all party lines in 1990; SaskTel was at the forefront of Internet provision as the first in Canada to remove the long distance charges on dial-up Internet and the first in North America to offer high speed service on phone-lines through DSL technology; and SaskTel was among the first commercial users of fibre-optics in the world (SaskTel, 2004). SaskTel's early experience with fibre-optics and converged networks (voice, data and video on the same network) led to the development of SaskTel International in 1986, which generally served as an international consulting agency and contractor for converged networks.

In many ways, SaskTel was able to pursue a consistent 'technological agenda' because it was free from the constraints of private capital markets and federal regulation. As cited previously, the Devine government recognized the value in providing SaskTel 
the regulatory freedom to fund the deployment of advanced services through crosssubsidization. Thus, SaskTel remained the primary common carrier in the province until 1986, when it sold its coaxial cable network to the various television distributors throughout the province. However, the legacy of the common carriage has remained and has, indeed, become the model for competition in the new millennium. The story of SaskTel's broadcasting distribution efforts provides an excellent foundation for a discussion and analysis of the current position in which SaskTel finds itself.

\section{SASKTEL THE COMMON CARRIER}

The notion of "common carriage"-that one company can carry several types of information on one network-is central to SaskTel's development and to this analysis. The story of SaskTel's move into broadcast distribution best illustrates the intermarriage of new technology, federal regulation and a shifting marketplace. This will provide a back-drop for a closer analysis on how new technology, politics and competitive markets are affecting SaskTel's ability to meet it's social objective to provide quality communication services to the people of Saskatchewan.

SaskTel's first brush with broadcasting occurred in 1957 when they constructed a portion of the trans-Canada micro-wave relay network. This network of micro-wave towers carried the first trans-Canadian television broadcasts-although, SaskTel had nothing to do with the content of broadcasts. This marked the beginning of SaskTel as a multi-media carrier. SaskTel's involvement in broadcasting remained stagnant until July 15, 1976. It was then that the CRTC granted broadcast distribution licenses (cable television) to six different Saskatchewan applicants. The success of these applicants 
relied entirely on the CRTC's acceptance that SaskTel was going to construct and maintain the coaxial network over which the television signals would be distributed. This posed a significant challenge to broadcasting policy, as governments were generally not permitted to assume any non-educational broadcasting activities, aside from the federally mandated Canadian Broadcasting Corporation. This generally accepted restriction on government broadcasting dates back to the late 1940's, when several provincial governments were denied the right to establish radio stations by the federal government (Babe 204). However, the CRTC recognized the logistical hurdles of a sparse, rural population and granted approval to the plan, stipulating that the licensees must own the 'drop' lines into houses, the local 'head-end' receiving and distributing equipment, and the equipment that might be used to alter the signals in any way. The CRTC language in the pre-amble to their decision demonstrates the 'special circumstances' it viewed as justification for its decision to accept SaskTel's involvement.

...the Commission recognizes the historic role of the provincial carrier, Sask-Tel, in providing telecommunications services to the remote areas of the province, through cross-subsidization of the service to scattered and isolated communities and individuals by the densely populated and economically viable urban communities. (CRTC 1976, 156)

It is important to recognize that through the mention of cross-subsidization in this passage, the CRTC implied that SaskTel should work to expand the television network beyond the communities of the original applicants-which were all urban centers.

At this point, it is important to note that two of the successful applicants were cooperative organizations. Co-operatives played an important political and economic role in the development of Saskatchewan and it is fitting to the prevailing political ideology that Saskatchewan citizen's first efforts to adopt cable television were through non-profit 
organizations. The Cable Regina application signals the centrality of the co-operative approach in their licence application:

Saskatchewan's vast land area, combined with a climate which at times is harsh, and its sparse population are no doubt factors that brought its people to rely on co-ops and its government to develop unique solutions to problems. No doubt resentment of Eastern Canadian institutions and the Federal Government controlled by Ontario and Quebec also contributed to the desire of Saskatchewan people to do things their own way. It is not unusual, therefore, that Saskatchewan people in the four cities now eligible for cable systems would, through a cooperative form of organization and in co-operation with their crown corporation Saskatchewan Telecommunications, come forward and ask the Canadian Radio Television Commission to allow them to offer a new approach to cable television service. (5)

The CRTC even paid notice to the co-operative applicants when they wrote:

The Commission is aware of the historic role of co-operatives in the economic and social development of Saskatchewan... The success of the co-operative movement in the province lies in genuine co-operative enterprises in which the members have a strong economic as well as social interest. $(1976,156)$

Cable co-operatives were ideologically suited partners for the government-owned

SaskTel. In fact, in their 1977 annual report, SaskTel expressed both their ambitions to be the carrier of cable television in the province and their reservations regarding the conditions imposed on them by the CRTC in decisions $77-432$ through $77-435$. They wrote:

The hardware ownership conditions imposed by the CRTC were not acceptable to SaskTel. The Corporation views it as an erosion of its role, as a public utility and common carrier, which is to deliver telecommunication signals in Saskatchewan. $(1977,7)$

The role of SaskTel as the sole communications common carrier in the province was not in synch with the wishes of the CRTC. Progress on the provincial cable network was minimal following the initial CRTC decisions. 
More than a year after the CRTC's decision in 1976, there was still no cable service available in the regions of licensees and The Battlefords Community Cablevision Co-operative went back to the CRTC with a request in hand. They could not come to an economically suitable arrangement with SaskTel regarding the cost and ownership of various components of the new cable network. Therefore, The Battlefords Community Cablevision, with the consent of SaskTel, applied to the CRTC to remove the license requirement that they must own the local head-end, the amplifiers and the drops to subscribers' houses, and simply require that they own the local head-end equipment. This proposal gave effective ownership of the distribution infrastructure to SaskTel, while cable companies would simply act as the signal modifiers and customer service agents. Although expressing reluctance, the CRTC decided to approve the request on September 15,1977 . In their decision they wrote:

... a cable television licensee should own its head-end, amplifiers and drops to ensure compliance with federal broadcasting legislation and regulations... In view of the special circumstances of Saskatchewan and the Commission's desire to avoid having potential viewers penalized by further delays, the Commission is prepared to adopt alternative means to achieve these policy objectives. (1977, 585)

It is important to recognize the reluctance of the CRTC in this decision. Although there is no reason to assume that The Battlefords were trying to circumvent broadcasting regulations, the CRTC was likely more concerned with the fact that a provincial government agency was entering the broadcasting realm. By 1977 , broadcasting and, to a lesser extent, telecommunication regulations were arguably under the jurisdiction of the federal government and the CRTC. The CRTC could have interpreted SaskTel's involvement as a potential challenge to their jurisdiction. This is likely why the CRTC used language referring to the licensee's capability to comply with federal broadcasting 
legislation and regulations. In this decision, it was also stipulated that the contractual agreements between The Battlefords Community Cablevision and SaskTel must be reviewed and accepted by the CRTC. It is curious that this jurisdictional concern was expressed, as SaskTel, among other publicly owned telecommunication providers, routinely dealt with CRTC on the telecom side. Perhaps this issue speaks more to the divisions between broadcasting and telecom bodies within the CRTC. However, the jurisdictional concern was not paramount as the CRTC also stated that:

... a provision could be included authorizing the cable television licensee, if availability and technical capability permit, to allow Saskatchewan

Telecommunications to utilize capacity in the inside wiring furnished by the licensee if so requested by Saskatchewan Telecommunications and approved by the federal licensing authority. (1977, 585-2.iv)

Following closely on the heels of decision 77-585, the licensees for Regina, Saskatoon and Moose Jaw applied for and were granted similar exemptions from ownership. Thus, with a trace of apprehension, the CRTC granted SaskTel the leading role in the development of cable television in Saskatchewan.

\section{Pioneering the Digital Revolution}

From 1977 through to 1986 , SaskTel quickly expanded the cable network to cover many small communities within the province. In the initial stages of construction, SaskTel used standard coaxial cable for the delivery of cable signals. However, the television infrastructure blossomed in 1980 with the planned expansion into 16 new communities and the acquisition of Prince Albert's cable system. In the same year, SaskTel also began the installation of a Broadband fiber-optic network (BBN) that was designed to carry both telephone and television signals throughout the province-a 
network that, once finished in 1984, was the largest of its kind in the world. Regarding their acquisition of Prince Albert's system, SaskTel wrote that:

This acquisition will strengthen the corporation's position as the designated common carrier for all telecommunications signals, including local cable $T \mathrm{~V}$, in the province of Saskatchewan. $(1980,8)$

Their intention to plan, own and operate the telecommunications infrastructure for the entire province was made stunningly clear. With the construction of a multi-purpose, fiber-optic network, SaskTel was already pushing into the digital age, which included the carriage of television signals on their switched digital network. Television distribution requirements helped to justify the broadband activities of SaskTel and pushed the expansion and development of their network. In their 1981 annual report, SaskTel wrote that:

While initially expanding cable TV to many communities and allowing SASK TEL to meet more traditional customer demands for telephone services, the BBN will ultimately pave the way for a host of new and exciting consumer, industrial, and educational services... This marked the first time anywhere that a commercial intercity fibre optic network was used to carry cable television signals. $(1981,12)$.

Quickly following the introduction of fibre optics to their television distribution, SaskTel also began digitizing the television signals they relayed using micro-wave networks. It should also be noted that SaskTel began using Telesat to assist with their distribution system in 1982 . However, in 1986 SaskTel decided to sell their local cable distribution systems to the various cable operators in the province. It is important to note, however, that SaskTel did not sell-off any of the micro-wave, satellite and fibre optic components, but strictly the local coaxial distribution systems. Most of the television signals in the province were still transmitted between local head-ends through SaskTel's network. In the same year, SaskTel International was formed to offer the expertise of the crown 
corporation abroad-including their expertise in digitally integrated telephone and television signals.

In 1989, SaskTel, in cooperation with Fundy Cable of New Brunswick, began their first long-term international project to develop an integrated television and telecommunications system in Leicester and Loughborough, England (LCL). In 1990, SaskTel also became involved with a British cable developer called Telecable Inc. A year later, in their 1991 annual report, SaskTel wrote:

SaskTel's equity position in two projects in the United Kingdom offers the prospect of long-term financial benefits for SaskTel and valuable experience in the home entertainment industry. $(1991,18)$

It seems that although they appeared to distance themselves from the local Saskatchewan TV market, they were very much interested in the 'entertainment industry.' In 1994, the word 'convergence' finally emerged in SaskTel's vocabulary. The 1994 annual report reads:

LCL also provides SaskTel with additional experience and technologies that can be applied as convergence nears between cable TV and telecommunications companies in Canada. $(1994,6)$

\section{Preparing For the Fight-Looming Competition}

At this point, it is necessary to step back from the progression of SaskTel for a moment and recall what was happening in the Canadian industry as a whole. In 1992, long-distance competition was ushered into the Canadian telecommunication system. As this challenged SaskTel's monopoly position in Saskatchewan, negotiations proceeded between SaskTel (backed by the Saskatchewan government) and the CRTC (backed by the federal government) to determine what would happen in Saskatchewan. SaskTel managed to negotiate a five-year moratorium from the complete jurisdiction of the CRTC 
in order to develop a strategy to comply with the various federal regulations and decisions. Thus, SaskTel still enjoyed a monopoly position in the province until 1997. As described earlier in this paper, the Canadian and North American communication industries were undergoing rapid, turbulent changes in response to both technological and economic pressures. Because of their historic dominance and protected position, SaskTel enjoyed an unparalleled five-year opportunity to organize themselves for the coming competition. It was during this period that SaskTel began playing with new broadcasting technologies within the province-technology that was largely developed through the projects of SaskTel International.

The burgeoning demand for digital interconnection also exploded in this 'buffer period' of the 1990's as a result of the Internet. Even though several different cable operators in the province began to offer broadband Internet service, they were only connected to the rest of the international telecommunications network through SaskTel's network. Secondly, through their extensive fiber optic network, a result of both their television and telephone distribution requirements, SaskTel managed to be the first company in Canada to offer broadband Internet commercially on existing phone lines through asymmetric digital subscriber line (ADSL) service in 1996. That meant that SaskTel became the first communication company to carry broadband Internet signals, voice telephone signals and television signals. Based on their 'convergence' talk in 1994, it was only a matter of time before SaskTel actually offered television service directly to its customers.

SaskTel's push into the digital television market arguably hit full stride with their Video-on-Demand (VOD) experiment in Regina in 1993. Through their fiber-optic 
network, they offered streaming videos, as demanded by the customer. Although somewhat different in nature than traditional broadcasting, there was considerable confusion within policy circles about whether the CRTC could assert jurisdiction over VOD services. Ultimately, the CRTC did assert jurisdiction over the service when it 'licenced' a number of Canadian companies to operate VOD services in specified jurisdictions. In 1993, SaskTel simply proceeded with their experiment with what appears to be little regard for the CRTC. This experiment blossomed to become the Hospitality Network Canada Inc. which now provides VOD and gaming systems within hotels and hospitals throughout Canada.

In 1997, the CRTC finally cleared the way for cable and telecom companies to compete head-on with Telecom Decision 97-8. Essentially, the decision established the conditions for local telephone competition, paving the way for reciprocal competition in the television distribution market. As you will recall, 1997 also marked the end of SaskTel's five year moratorium. Indeed, long-distance competition was eventually ushered into the province, but SaskTel did not fall fully under CRTC jurisdiction until June 20, 2000, as Premier Roy Romanow managed to procure a two year extension on the moratorium in 1998. It was the following year that SaskTel made its bid to become a : full-scale broadcast distributor in Saskatchewan.

On March 12, 2001 SaskTel's application to operate a digital broadcast distribution undertaking (BDU) in 12 of Saskatchewan's largest communities was approved by the CRTC. The significance of the SaskTel undertaking rests in its interactive nature. The SaskTel application promised to deliver both broadband Internet service and digital television through one wire and one set-top-box. Thus, it was a true 
marriage of television and the Internet - the first of its kind to become commercially available in North America. It was the service that all industry players had promised through digital convergence-yet no other company had managed to deliver. The CRTC called the service digital interactive video (CRTC 2001-71). The service was actually launched on September 12, 2002 and received surprisingly little press coverage. However, the launch of SaskTel MAX service raises many questions about the nature of the communications industry in Canada.

\section{COMMUNICATION (R)EVOLUTION}

The communications industry is currently subject to a very rapid evolution in Canada. SaskTel is a unique position as both a major incumbent carrier and a provincially owned crown corporation. Their position as a crown corporation places social obligations and political scrutiny on their activities. Conversely, the CRTC now regards SaskTel as another incumbent carrier and former monopoly that must yield some market share through the pro-competition measures they visit upon all incumbent carriers. Amidst this limited operating space, SaskTel is also feeling the impact of technological change in the industry-especially the roll-out of Internet Protocol (IP)based services that threaten to undermine the current Publicly-Switched-TelephoneNetwork (PSTN). From the Saskatchewan perspective, the state of the public interest in Canadian communication policy must consider three things: the state of the communications industry in Canada; the state of SaskTel's relationship with the CRTC; and the state of SaskTel's current relationship to the provincial government. An account of these three variables, drawing on both the previously provided history and the 
evolution of common carriage in SaskTel, will permit the concluding remarks on the state of the public interest in communication policy for the people of Saskatchewan.

\section{Uncertain State of the Industry}

Saskatchewan residents can now download 'virtual phone' for free from an American based software designer and make several long distance calls to friends and family members through a New York based telephone number using their computers-no fees, no long distance charges and no geographical constraints. Several companies, including American providers, are now selling "IP phones" in Canadian markets that, when connected to any high-speed Internet connection, will permit a user to make and receive telephone calls to or from any regular telephone number, entirely bypassing the normal toll structures and geographical routing procedures that define the PSTN or the 'normal' telephone system. The all-digital signals are being routed through the Internet and then connected to the PSTN at the location of that service provider's Internet servers. Take my original example: I can make phone calls through my computer using a SaskTel high-speed Internet connection that sends my voice, in digital IP packets to Stanaphone ${ }^{\mathrm{TM}}$ Internet servers in New York, where they are tied into the PSTN which routs the call bačk to my parent's house in Saskatchewan on the traditional phone network and terminates at their normal telephone. The significance of the technology is that I pay no long-distance fees to SaskTel, or any other carrier, for routing the call. This new "disruptive technology", which is finally delivering on much earlier promises of digital convergence, is causing both panic and jubilation throughout the communications industry. While SaskTel was a pioneer in the development of converged networks, most communication carriers did not evolve in the same fashion. 
While there has been substantial competition in the digital television distribution market and Internet provision in the past ten years, the local telecommunications market has remained well within the control of incumbent service providers, much to the disdain of the CRTC, the cable companies and new entrants to the market. Until the introduction of IP services, providing local telephone service was an expensive and inefficient venture for new entrants. With IP telephony, new competitors can now offer virtually a full range of communication services to anyone who has a high-speed Internet connection. It may be that we are now witness to the beginning of a truly competitive communication system that is subject to competition in all services: television, wireless, voice and data. IP telephony has certainly spelled the end of long distance charges and geographical constraints as we know them. However, recent history in the industry teaches caution over unbridled enthusiasm.

In the 1990's a flurry of telecommunication, broadcast distribution and massmedia mega-mergers erupted based on the arrival of digital DTH broadcasting. John Malone, the American cable baron, is credited with promising the ' 500 channel universe' in the digital age. (Fraser 3) Malone's pronouncement in 1992, prompted by the impending introduction of the all digital direct-to-home satellite broadcasting venture launched by DirecTV, sparked a whirlwind of over-hyped promises of what the 'digital age' would offer consumers. "Convergence" became the buzzword of the communication industry and it carried with it a twofold meaning. Firstly, the digitization of information meant that, once information had been digitally coded into 1's and 0's, all information was essentially the same. Video, audio and text information could all be reduced to the same format-a highly compressed, efficient code that could be 
transmitted by many different means, including copper wire, micro-wave systems, satellite systems and over-the-air broadcast systems. This development suddenly pitted telecommunication companies and cable companies as direct competitors for the distribution of information, when they were previously distinctly separate industries. This technological convergence instigated a serious and sudden wave of economic convergence throughout North America's communication industry. Information carriers and information producers joined to form massive, vertically integrated companies that both produced and distributed their own information. Throughout the 1990's, bigger was better, and the consumer was promised everything.

There are two consequences of economic convergence in the Canadian communication industry. Firstly, the different types of communication carriers (ie. cable, DTH and telecom) were lining-up to compete with each other in the distribution arena. Secondly, the same companies were seeking vertical integration so they might become producers and suppliers of the information that they also carried. These were two distinct, but closely related economic pressures that sparked the various transactions that occurred. Canadian ownership requirements ensured that Canadian media and communication properties remained under Canadian control. However, Canadian communication and media titans did scramble to produce a few tightly held communication behemoths. In his 2002 publication Kings of Convergence, Gordon Pitts chronicles the first round of economic convergence among Canadian carriers and media conglomerates. Pitts writes, "The year 2000 saw an avalanche of deals that were not inspired by any sure-footed business model-they were bets, informed and calculated bets, on whether certain visions of the future would ever work out." (10) 
This round of convergence produced a collection of five vertically integrated media 'behemoths' in Canada, according to Pitts: Canwest Global, owned primarily by the Asper family; Shaw Cable, owned primarily by the Shaw family; Roger's Cable, controlled largely by Ted Rogers; Quebecor, controlled by Pierre Karl Peladeau; and $\mathrm{BCE}$, the publicly traded communication leviathan. For these players, the concern was how to capture consumer dollars in the uncertain evolution of new communication technology. Pitts describes the efforts as follows:

Each of the players began with a slender conduit into the house - a telephone wire, in the case of BCE; coaxial cable for Rogers and Show; broadcast licences for the Aspers; newspapers and TV signals for Quebecor. The challenge was how to leverage that entry point into an array of indispensable services, to add pieces, as in a puzzle, to create the must-have blend of properties. Nobody was able to put together the whole puzzle. (10)

The last line of this quotation foretells the short-term outcome of these 'bets'. The vertically integrated companies have, at best, come close to accommodating the debt they incurred through integration. Very little changed for the consumers of communication and media services-no one felt the fruition of technological convergence. However, VoIP technology has now married broadband Internet with telephone service and digital wireless services have exploded in the past four years.

We are now witnessing the arrival of IP-based communication services, and it has sparked a second round of convergence among Canadian carriers. Michael J. Sabia, President of Bell Canada Enterprises, recently stated that "...the age of Internet Protocol-or IP-is dawning... IP is the communications lingua franca of our generation. It allows any device to deliver any information in any format. Voice. Data. Video. All over what is essentially a single network." (BCE 2004, 2) Although the first round of convergence activity was predicated by verbal hype regarding technological 
possibilities that never materialized (except for SaskTel MAX), various IP-based technologies are actually being offered now. Real competition among all carriers including satellite, telecom, cable and wireless has now arrived in most parts of the country and the industry players are, once again, attempting to establish themselves firmly at the forefront of the industry. MTS, Bell and Telus have all made successful acquisitions or have offers pending on residual Canadian communication carriers which will pit the three carriers against each other in the competitive business and commercial communication market. ${ }^{1}$ Since the April, 2004 release of the CRTC's Public Notice 2004-2 for the VoIP proceeding, the business headlines in Canada have speculated the arrival of heated competition as former allies in the telecommunication sectors appear to be squaring off, while cable companies and wireless providers are waiting in the wings to exploit the carnage that may unfold.

Amidst the battlefield sits SaskTel. With ambitions to continue offering the highquality converged communication services it pioneered in Saskatchewan, there are several variables that must be successfully accommodated. Firstly, SaskTel is now treated as a large Incumbent Local Exchange Carrier (ILEC [the incumbent telephone company in its respective region]) and is subject to the same regulations as Bell, Telus and MTS-all of which are much larger, publicly-traded companies. As a result, some of the regulatory constraints placed on SaskTel do not necessarily recognize the unique social obligations and market conditions which SaskTel must accommodate. Secondly, SaskTel continues to be subject to political influence from the provincial government and the Saskatchewan population. Just as the CRTC fails to currently recognize the unique

\footnotetext{
' See Carriers Face Fierce Battle: Cable Companies pose Biggest Threat, Naional Post, June 15, 2004, p. SR1
} 
circumstances of SaskTel in their regulatory decisions, Saskatchewan citizens and politicians do not appear to understand the regulatory and market constraints to which SaskTel is now subject.

\section{Crown Jewel or Public Enemy?}

The recent shift to CRTC jurisdiction has certainly mitigated the capacity of the Saskatchewan government to direct the policies and course of SaskTel. Yet, the strong political character of the province and its people continues to exert influence on SaskTel through the political arena: indeed, the province still owns the company. Thus, activities of the company are heavily scrutinized by both the public and political opposition. Since the advent of competition in the communication industry, coupled with the imposition of federal regulation, SaskTel has gradually diversified its investments and business activities to develop alternative sources of income to meet its public policy objectives in the province of Saskatchewan. Among the various crown corporations, this has made SaskTel a frequent target of political criticism for straying from its "core services". In short, SaskTel is both the "poster child" and the "whipping boy" of Saskatchewan politics. It has managed to meet its public policy objectives and technological feats, for: which it is lauded, while it has necessarily expanded beyond the Saskatchewan borders, which does not necessarily sit well with the critical public-especially when the company's investments do not work out.

When competition was ushered into the industry in the late 1980's and early 1990's, SaskTel and the Saskatchewan government scrambled to develop a strategy for maintaining the state of their communication system. Like the rest of the industry, SaskTel traditionally relied upon healthy long-distance revenues to subsidize the cost of 
local service. Secondly, they provided cross-subsidization of rural and remote areas with revenue from other markets-another standard practice at the time. When competition was officially ushered-in in 1992, SaskTel began the complicated dance of meeting their social policy obligations while operating a profitable corporation that adhered to new regulations. Perhaps the trickiest step in the dance was mounting a consistent public relations campaign to fully inform Saskatchewan citizens of the new and changing regulatory constraints on the carrier. In 1992, the SaskTel annual report explained that:

"The realities of a more competitive world mean that SaskTel must design and implement new strategies to counter its revenue losses... During the year, a significant event took place that fundamentally changed the nature and structure of the Canadian telecommunications industry.... Although the CRTC decision does not currently apply in Saskatchewan because SaskTel is a provincially owned crown corporation, it will still exert considerable new pressures on our company." $(1992,2)$

In addition to extolling the hardships of new regulation, SaskTel also worked to assure citizens that their primary commitment, despite their external business ventures, was to serving Saskatchewan. In the 1995 annual report, it states that:

Saskatchewan is different, because access to telephone service has always been a community-based public good here... effective telephone service, accountable to the people and available throughout the province, continues to be an identifying and binding characteristic of Saskatchewan. The preservation of this communications clause in the Saskatchewan social contract-not the preservation of SaskTel's revenues-is what should be on our minds as we invite new entrants into the marketplace. $(1995,7)$

This chorus for the public continues to this day as SaskTel continually works to justify its business activities that stretch beyond the Saskatchewan borders while ensuring that their primary commitment is to the province.

According to most accounts, the role and future of Saskatchewan's crown corporations was the central issue in the 2003 provincial election. Much of the election 
campaign was a tit-for-tat battle between the incumbent New Democratic Party (NDP) and the Saskatchewan Party over who would sell or retain the crown corporations and under what conditions. The battle over "crowns" is as much a battle over political ideology as much as the management of particular corporations. Saskatchewan residents have seen the coming and going of both a nationalization campaign under Alan Blakeny and a privatization campaign under Grant Devine, and the role of crown corporations in the province seems to touch a political nerve with most people. Headlines in both major Saskatchewan newspapers (The Regina Leaderpost and The Saskatoon Starphoenix) suggested at the onset of the election that the role of 'the crowns' would dominate the campaign.

Indeed, the campaign trail erupted in mid-October when it was reported that Saskatchewan Party leader Elwin Hermanson had implied that they would consider selling the crowns, and specifically SaskTel. A Leader-Post article from October $28^{\text {th }}$, 2003 entitled What they said: Crowns the focus once again stated:

The future of Saskatchewan's publicly owned utilities has been a hot topic since NDP Premier Lorne Calvert dropped the writ. The NDP maintains it is committed to Crown corporations that will provide customers with the lowest utility rate packages in Canada. The Saskatchewan Party has said it has no plans to sell off SaskTel, SGI, SaskPower and SaskEnergy, but other "non-core" Crown investments could be sold if good offers were received But when the Saskatchewan Party's platform was unveiled, Hermanson also said the party "would be crazy" not to listen to offers that would benefit the province

The Saskatchewan Party spent most of their campaign denying they would sell the major crown corporations, while the NDP focused almost exclusively on that topic. University of Saskatchewan economist Eric Howe suggested that the debate in 2003 was simply a repeat of the same debate which saw the election of Devine in 1982. In an interview on $\mathrm{CBC}$ radio on October $27^{\text {th }}$, Howe characterized the debate as follows : 
... it's really understandable how we went from a society principally agricultural where services had to be provided by government run businesses. It's easy to see how that happened. It's then easy to see how we are in the situation we are in now. For we still have these government run businesses, but overtime we want to take, we should want to take the government out of that particular equation. But it has to be done slowly and deliberately. We just have a larger Crown Corporate sector here than is true in other provinces.

... If we change it in a precipitous way it's only going to hurt us more. It's going to be 1982 all over again. From the point of view of Premier Devine, it was that he was going to announce that we were open for business and this was going to result in private sector investors opening their coffers and large increases in provincial investment.

In fact, what resulted was a twenty percent, or nearly a twenty percent decline in provincial investment. Because when you make a major change in the regulatory and the institutional environment like tha, that creates uncertainty and investors find uncertainty frightening... It was clear that the policies weren't working. The response of the Devine government was to then just start investing in all sorts of things to try to get the economy back going again. (Howe 2003)

Thus, we see that the role of the crowns has been a bright political ember in

Saskatchewan for many years, and the ember continues to burn brightly today.

The narrow NDP victory has ensured a place for Saskatchewan's crown corporations in

the short term. However, the growing fortunes of the Saskatchewan Party indicate that not everyone in the province sees eye-to-eye with the NDP. The official opposition routinely raises questions about SaskTel investments and practices in the legislature. Because SaskTel's ownership structure effectively makes all Saskatchewan citizens de facto shareholders, it is understandable that issues sometimes enter the political realm. As would any diligent shareholder, the opposition party routinely raises concerns over poor yielding SaskTel investments. Most recently, SaskTel's losing investments in Persona, RetX and Navigata have been questioned by the public. ${ }^{2}$ The contention that SaskTel should stick to its 'core services' within Saskatchewan customarily follows the public release of losing SaskTel investment. People routinely refer to the investments as 'public money' or 'taxpayer's money'. On SaskTel's losses, opposition member Wayne Elhard stated:

The NDP (government) canceled almost all surgeries in the Saskatoon Health Region for the last two weeks in March to save \$200,000," Elhard noted. "As a

\footnotetext{
${ }^{2}$ See SaskTel's loss Slammed, Starphoenix, April 8 ${ }^{\text {th }}, 2004$, A4
} 
result, the waiting list for surgeries in Saskatoon increased by two months. "Then the NDP shorten summer by delaying the opening of provincial parks to save a mere $\$ 100,000$. But when SaskTel wants to gamble and lose more than $\$ 60$ million on bad business deals -- most of which are outside of Saskatchewan -there doesn't seem to be problem." (Starphoenix April 8, 2004)

People, then, often regard all SaskTel business as public business and, therefore, fail to recognize the business strategy of the entire SaskTel holding corporation (including its investments) which attempts to meet the needs of Saskatchewan citizens despite regulatory constraints and competition.

This begs the question of whether SaskTel is just a crown-owned utility provider in Saskatchewan, or a competitive service provider which just happens to be held by the province. SaskTel's vision statement declares that: SaskTel is a highly innovative and competitive communications solutions provider for our Customers worldwide, delivering sound financial returns and public policy benefits to the people of Saskatchewan. Our focus is our customer. Our strength is our people. (sasktel.com 2004) If anything, this demonstrates that even SaskTel has no clear-cut answer of its own. It currently rests between two distinct visions of communication provision. On the one hand, the federal regulator is pushing the development of robust competition in the entire communication sector, while on the other, the Saskatchewan government is continuing to assert its control over SaskTel as a tool for the delivery of political policies in the province.

Within the province, itself, there seems to be a deeply divided vision of the role of crown corporations and this was clearly reflected in the 2003 election coverage and results. An editorial in the Leader-Post on the eve of the election aptly characterized the political division in the province regarding the crown corporations.

Nowhere in this country -- nowhere on the continent, really -- is there a jurisdiction where there has been a greater philosophical divide between the natural governing party (the social democratic CCF-NDP that has governed for nearly 43 of the last 59 years) 
and the alternative (free-enterprise, right-wing parties like Ross Thatcher's Liberals, Grant Devine's Progressive Conservatives or Elwin Hermanson's Saskatchewan Party). Because we've lived this reality every day for the last six decades, we sometimes forget about it, but make no mistake that such political divisions have always cut deep in Saskatchewan. They cut right down to where you bought your milk and eggs (the local Co-op or the Red and White), where you bank (the Credit Union or the Bank of Commerce) or where you sold your grain (the Pool or the former UGG). And while such differences don't matter much when you're talking to your neighbour over the back fence, they are differences near the hearts of Saskatchewan people. More often than not in Saskatchewan, your vote is near your heart. So when NDP Premier Lorne Calvert says today, "As long as I am premier, our Crowns are not for sale," understand that he means it. This just happens to be one of those elections we have every decade or so when our philosophical differences are being profoundly expressed. (November 4, 2003, A8)

Despite this political divide, SaskTel remains the dominant and often the sole communication option for Saskatchewan residents. Therefore, even those who disagree with the business decisions of SaskTel and the philosophy of crown corporations must rely on SaskTel services. The economy of Saskatchewan rests mainly on the exportation of raw commodities and all those operations require communication in remote and rural areas from the grain belt of the south to the uranium minds of the north. In an increasingly global market, communication technologies provide the instantaneous connections to their markets that producers require. Rural farmers, especially, require constant connection to commodity markets throughout the world and the ability to quickly and efficiently deal with buyers across the globe. Thus, even critics of SaskTel in the rural areas seem to retain a measure of respect for the carrier, as they recognize the growing importance and fundamental need for the advanced communication services that only SaskTel provides them.

However, provincial political pressures are only part of the challenge for SaskTel. Although their history is rooted deeply in provincial politics, the heaviest pressures currently come from the federal government and an uncertain communication marketplace. 


\section{Small Fish, Big Pond-SaskTel on The National Playing Field}

Michael Sabia's public campaign to emphasize the growing importance of IP technology is primarily a rally against the CRTC, which has suggested that it will impair incumbent carriers from offering IP-based voice telecommunication services in the name of introducing viable competition to the communication industry. While the CRTC has not yet ruled on the regulatory framework for VoIP services, they have initiated a public proceeding on the topic. Their initial suggestion is that because VoIP services still use telephone numbers and essentially replace local telephone service that they should be regulated as such. The following excerpt from the Public Notice demonstrates the Commission's intentions:

Consistent with the principle of technological neutrality, in the Commission's preliminary view VolP services should be subject to the existing regulatory framework, including the Commission's forbearance determinations. It follows that the regulatory requirements imposed on VolP service providers would depend on the class of the service provider (e.g., ILEC, CLEC, non-dominant Canadian carrier, mobile wireless service provider, local service reseller) and the type of service being offered. Thus when ILECs provide VoIP services in their incumbent territories, they would be required to adhere to their existing tariffs or to file proposed tariffs where required, in conformity with applicable regulatory rules. CLECs, including wireless CLECs and ILECs out-of-territory, would not be required to file tariffs for retail local VolP services... (2004-2, 22-23)

The preceding passage explains that the CRTC intends to treat the incumbent telecos differently than new entrants when it comes VoIP services.

This fits with the CRTC's continued efforts to 'force' competition in the local telecommunications market through regulatory means. Thus, incumbents who introduce VoIP services in their own territories (ie. the province of Saskatchewan in the case of SaskTel and Ontario and Quebec in the case of Bell) will be subject to the same price 
constraints and tariffs as are currently applied to local telephone service. This essentially removes the incentive for incumbents to develop their own VoIP services that would coopt their current switched systems and would offer no significant financial returns because of the pricing constraints. Thus, a strange environment has recently developed in Canada where incumbent companies are competing with each other through new technologies outside of their territories, while they are not permitted to offer those particular services within their own incumbent territory. SaskTel is, in fact, the first incumbent to offer retail VoIP services outside of their territory through their Vancouverbased subsidiary Navigata ${ }^{3}$

Clearly, there is competition in most aspects of the Canadian communication system. Even in the sparsely populated province of Saskatchewan, there is competition in cellular service, broadcast distribution and, in some regions, high-speed Internet provision. However, competition in local wire-line service remains absent from Saskatchewan, and from most markets outside Canada's major urban centres-and this remains the contentious cornerstone of CRTC regulation. The spring and summer of 2004 was saddled with three CRTC proceedings that hinge on the Commission's approach to regulating local wire-line telephone service and incumbent telephone companies have riddled the business headlines with calls for reform.

The Voice-over-IP proceeding is the primary proceeding that has brought the current regulation of local wire-line service into question. The raucous debate over the wisdom of the Commission's pro-competition policy was sparked by the release of the Commission's preliminary views on the regulatory framework for VoIP services at the end of April, 2003. The quandary that regulatory framework imposes has already been

\footnotetext{
${ }^{3}$ As of June, 2004
} 
explained. There are two others, however, that also place the Commission's regulatory framework under scrutiny.

Aliant, the incumbent service provider in the Atlantic provinces, has applied for forbearance from local service regulation in some markets where their competitor, Eastlink Cable, has captured some of the market. Currently, the Commission regulates the prices that incumbents like Aliant can charge for their local services. The prices of regulated local service are normally reduced over time to account for efficiency gains. However, the Commission has limited the ILEC's price reductions so that there remains a sufficient profit margin to entice competitors to enter the market. To ensure that the incumbents did not also benefit from the inflated margins, the Commission forced them to direct the inflated portions of the profit margins that would have resulted in price decreases into 'deferral accounts' which would eventually be expended on appropriate measures to improve the telecommunications system as determined by the Commission (CRTC 2002-34).

The second current proceeding, the decision on how to spend deferral account funds, is where local competition regulations have become the central concern (CRTC PN-2004-1). Most competitors assert that, because deferral account funds and the price cap regime were intended to entice competition, that the funds should be spent on the development of common and competitive facilities. Call-Net, the parent company of Sprint Canada, a competitive local and long-distance carrier, offered the following rational:

12. While it might appear at first sight logical to return these funds to subscribers in the form of a rebate, this is not a serious option under the circumstances. In addition to being extremely difficult to administer in a fair and equitable manner, 
a rebate would defeat the very policy objectives that led the Commission to suspend application of the basket constraint in the first place...

15....part of the funds should be spent on expanding the availability of competition in areas where it is not yet available. By using the funds in this manner, the benefits of lower prices and increased choice will be made available in a shorter time frame to the wider group of subscribers who have contributed reverues to the deferral accounts. (Call-Net, 2004)

The policy objectives to which Call-Net refer, are five goals for which the Commission established the price-cap mechanism and deferral accounts to begin with. They are:

a) to render reliable and affordable services of high quality, accessible to both urban and rural area customers;

b) to balance the interests of the three main stakeholders in telecommunications markets, (i.e., customers, competitors and incumbent telephone companies);

c) to foster facilities-based competition in Canadian telecommunications markets;

d) to provide incumbents with incentives to increase efficiencies and to be more innovative; and

e) to adopt regulatory approaches that impose the minimum regulatory burden compatible with the achievement of the previous four objectives. (CRTC PN 2004-1)

Underlying these objectives is the notion that local competition will eventually benefit consumers through lower prices and innovative services. The irony, then, is that ILEC customers (over $95 \%$ of Canadian local lines are still provided by ILECs [CRTC November, 2003]), mostly because there are no competitors in their respective regions) now have more expensive local service in order to subsidize competitors who have not yet entered the market. The high price of the service has been artificially maintained for the ultimate cause of lowering prices and improving services. In their tersely worded submission to the deferral account proceeding, The British Columbia Public Interest Advocacy Centre (BCPIAC), a non-profit legal advocacy organization, sated:

5. Consumers of local residential service have so far been net losers in the reregulation of Canadian telecommunications. Regulatory change has not induced the introduction of competition into this market, and rate rebalancing has produced a large increase in the cost of service. Further, there is no reasonable 
prospect or expectation that this situation will be remedied in the foreseeable future.

6. It would be seriously inequitable if the Commission were to direct any of the accumulated monies, collected from local residential subscribers, for the benefit of CLECS who have shown no interest or inclination to enter this sector of the market.

8. Competition is, after all, a means to an end and not an end in itself. It would be entirely perverse to sacrifice the end (efficient and lower rates) in an attempt to induce the means. (BCPIAC, 2004)

SaskTel, in fact, has no money in its deferral account because they used the funds, with CRTC approval, to develop the technical capacity to accommodate competitors on their network. Despite the technical capability to now handle a local competitor, no companies have expressed interest in entering the local wire-line market in Saskatchewan. This is a strong indication that there simply is no market in Saskatchewan, or in many other regions, for facilities-based competition in local wireline service. SaskTel customers have paid for the availability of competition, yet no competition exists. To further confirm the absent Sasktchewan marketplace, we can refer to the most recent Dominion Bond Rating for SaskTel which states:

"(I) SaskTel's marketplace has weak fundamentals with: (a) negative population growth, (b) low population density, (c) high-cost service areas, and (d) low GDP growth...

(2) SaskTel's regional size limits economies of scale and higher margins.

(3) Declining margins with the expansion of lower margin broadband and wireless services combined with a decline in traditional high margin voice business.

(4) Rapidly changing technology with the introduction of Voice over Internet Protocol (VOIP) will threaten SaskTel's stable local and long distance voice businesses, which provide high margins. Over the medium term, the introduction of VOIP by cable competition represents SaskTel's greatest competitive challenge." (Dominion Bond Rating Service Ltd., 2004)

As a competitive marketplace, Saskatchewan is unattractive at best and the future is unlikely to see competition through any other means than IP-based services. And in rural 
Saskatchewan, the only IP network which could deliver those new services belongs to SaskTel.

\section{The Price of Competition}

There is competition in certain services, like long distance and cellular, which do not require the installation of substantial physical facilities. However, the Commission continues to pursue facilities-based competition, as stated in (c) of the previously listed policy objectives of the price-cap decision. Why facilities-based competition? The rational is that incumbents own "bottleneck" facilities, like the final wires into people's homes, which would be economically impossible for a competitor to duplicate: they would have to rip-up streets and sidewalks in every neighbourhood in order to install their own network. Thus, the only way, to introduce long-term, sustainable competition is to assist competitors in developing alternative physical networks by increasing margins in the business, and by forcing incumbents to share their networks at cost in the hopes that competitors will eventually invest in physical network components. However, the Commission, itself, has admitted that the effort to introduce facilities-based local competition has failed. In providing the regulatory framework for the second price cap : period, the Commission wrote:

58. In the residential market, however, virtually no competition developed during the initial price cap period, with the limited exception of some areas in the Maritimes. Overall, competitors achieved minimal market share in residential basic local exchange services.

59. In addition, there was no evidence to suggest that competitors had made any inroads into the market for residential optional local services. On the contrary, the ILECs were able to increase revemues from these services through rate increases without experiencing a significant reduction in demand.

60. The Commission considers that competitive entry into the residential market will contimue to be limited in the foreseeable future. Based on the record of the present proceeding, it is unlikely that the larger cable companies will enter the 
residential market in the near future on any significant scale. (CRTC Decision 2002-34)

This excerpt demonstrates two issues. Firstly, it demonstrates the failure of the Commission's approach to introducing local competition while it then continued to apply the same approach. Secondly, it demonstrates the Commission's past unwillingness to recognize the full effect of new technologies on the communication system. Cable companies have now announced their intentions to compete in the local telephony market, and several services, like VoIP and wireless, arguably permit competitive substitutes for local service. Yet, even in their preliminary regulatory framework for VoIP, the Commission continues to handicap incumbents, including SaskTel, in the name of competition. SaskTel's customers will continue to be the end losers, as local competition, as defined by the Commission, fails to arrive and to offer the substantial benefits to consumers that the Commission promises it will.

SaskTel's current position is akin to the other incumbents and they have joined the growing chorus for regulatory reform. Historically, SaskTel relied on the political support and protection of the provincial government in its disputes with the CRTC. However, they have now embarked on an independent campaign to sway federal policy : makers, as the provincial government can no longer offer the protection that it once did. In a 2004 letter to then Industry Minister Lucienne Robillard, SaskTel president Donald Ching wrote:

SaskTel is concerned that government policies and the regulatory regime are not evolving at a pace and in a direction that will allow our sector to fulfill its potential as it regards the development and deployment of this leading edge technology. Failure to rebuild the policy and regulatory framework will put the historic strength of communications companies like SaskTel at risk. (SaskTelChing 2004) 
SaskTel's call for reform was repeated to Saskatchewan's lone Liberal and federal cabinet member, Ralph Goodale. Ching wrote:

SaskTel is now of the view that without meaningful regulatory reform, the future is dimming for the communications industry in Canada and ultimately SaskTel, with consequential impacts on all stakeholders including customers and employees. (SaskTel-Ching, 2004)

SaskTel's alliance with Bell on this issue provides it added weight. However, communication policy essentially dropped from the agenda during, and since the June 2004 election of a Liberal minority government. With limited public appeal and concern, it is difficult to determine if communication policy will garner much attention in the near future. Thus, carriers must continue to work with the CRTC and its current policy direction, which is still somewhat uncertain.

In a June, 2004 speech to the Canadian Telecom Summit in Toronto, CRTC Chairperson Roger Dalfen explained that the Commission recognized that the industry was experiencing a sudden tide of convergence that. He stated that:

Sectoral convergence has become a fact of life in the industry. The concept has lived down the bad name it acquired in the 1990s when its potential-promoted, hindsight tells us, with premature enthusiasm-went largely unrealized. Today, though, cable companies and telecommunications companies routinely offer services that were previously the preserve of the other, with important consequences for competition. (CRTC-Dalfen 2004)

The consequence, concluded Dalfen, is that the distinctions between local competition and other services was fading, an argument made by the incumbent telecom carriers. He went so far as to state that, "For our part, we look forward to moving toward the deregulation of local telecom services, as and when market conditions permit (author's emphasis added)." Thus, uncertainty remains regarding the appropriate market conditions according to the CRTC. If their definition of local facilities-based competition 
fails to include VoIP and/or wireless services, there is little chance the current regulatory framework will change. This could have devastating effects on the operations of SaskTel as it will continue to be handicapped in offering of new services within Saskatchewan, while competitors will be permitted to use SaskTel's network, at discounted rates, to deliver competing and innovative IP services. All the while, the development of competitive 'facilities' will likely lag in the marginal Saskatchewan market, while the excess revenues from SaskTel's local service customers will continue to fund competitive efforts. Ultimately, it could place SaskTel's capacity to meet its social policy obligations in serious jeopardy.

In understanding the state of the industry and SaskTel's position within it, there remains one question: why is the CRTC pursuing the development of competition in local telecommunication service at virtually any cost?

\section{Regulatory Roots of Competition}

Robert Babe clearly established that the federal government has generally supported the regime of regulated monopolies since the quashing of competition in 1881 when charter privileges were conferred on the Bell Telephone Company of Canada through an act of Parliament (135). It was, in some ways, technological convergence that initiated the re-emergence of competition in communication distribution in 1976. While SaskTel was petitioning the CRTC for the right to distribute broadcast signals, CNCP Telecommunications was requesting that the Commission force Bell to provide them access to switching centres and local loops. CNCP, which was historically a telegraph company, had migrated into the business of data transmission and felt they were disadvantaged by Bell's refusal to interconnect. CNCP won CRTC support for 
interconnection with Bell in May of 1979. In that decision, the CRTC foreshadowed the policy rational that would become commonplace:

The evidence in this case indicates that competition would be greatly enhanced with interconnection [and that] interconnection would provide significant benefits to users in terms of improved responsiveness, particularly on the part of the telephone company, in satisfying their telecommunications requirements. (Report $102-51976,241-42$ )

This interconnection decision was followed by two more in favour of $\mathrm{CNCP}$ : one for interconnection with $\mathrm{BC}$ Telephone Company and the second for interconnection with Alberta Government Telephones (AGT). The AGT decision touched on the common Canadian political concern of government jurisdiction, as the CRTC was a federal body and AGT was provincially owned. Accordingly, the case was eventually heard in the Supreme Court in 1989, nearly 7 years after CNCP's application for interconnection. The Supreme Court offered a routinely nebulous ruling that, indeed, telecommunication services were 'interprovincial' in nature and that the federal government, therefore, held authority to regulate them accordingly; but that as a provincially owned utility, AGT enjoyed Crown Immunity (Babe 132). The decision effectively affirmed the federal government's right to regulate the communication industry, while it provided some room for the provincially owned carriers to come to agreements with the federal government regarding their status. As mentioned previously, SaskTel capitalized on the principal of Crown Immunity until 2000. However, SaskTel had to weather the introduction of both long distance and local competition during that timeframe.

Long distance competition was introduced in 1992 (CRTC Decision 92-12), and local competition followed in 1997 (CRTC Decision 97-8). Although the introduction of long distance competition was largely a progression of the CNCP interconnection 
decisions, Decision 92-12 not only heralded local competition, but competition between cable companies and telecom carriers. It was this decision that opened the Pandora's Box in communication regulation.

In response to the mounting pressures of convergence in all sectors of the Canadian communication industry, the federal cabinet commissioned the CRTC in 1994, through an Order in Council, to "gather information, seek input, provide critical analysis and report to the Government on a number of matters, as they relate to the Commission's area of responsibility, respecting the development of content and competition policies for new communications technologies and services that will comprise the "information highway". (OiC P.C. 1994-1689) The resulting CRTC document entitled Competition and Culture on Canada's Information Highway: Managing the Realities of Transition essentially launched the transition from a monopoly protection policy to a procompetition policy in both broadcast distribution and telecommunications. The following passage from the report provides an excellent example of the justification for competition which is always accompanied by a cautionary disclaimer:

Competition is generally recognized as the best means of stimulating choice, innovation, efficiency, better service, lower prices and economic growth. However, increased reliance on market forces must take into account the other objectives of broadcasting and telecommunications legislation. For example, the benefits of competition may not extend equally to all subscribers in all regions. Some form of subsidization will likely be required to assure affordable access to the information highway. (Ch. 2)'

This passage demonstrates the significant policy impacts of digitization and convergence.

Firstly, there is an inherent acceptance that carriage of communication, both telecommunications, broadcasting and everything in between, is now a common characteristic of any communication transmission network. The case put forth for 
competition is that the public, as consumers of information and users of delivery networks, will benefit from more choice and lower prices. Thus, communication carriage will be reduced to a consumer good very much like any other. Perhaps this is an example of how the state will remove any traces of coercion from public communication. Alternatively, it could be viewed as a failure of the state to protect the Canadian public sphere from the harmful influence of concentrated private control over the means of communication.

Public interest is more clearly lodged in access-ensuring that everyone has at least some access to communication technologies. Granted, the preceding excerpt is a virtual admission that where there is no market, there will be not competition and, indeed, no service. In fact, competitive policies have arguably degraded access to communication technologies in some circumstances. Since the introduction of competition in local telecommunications, some incumbent carriers have begun removing high-cost pay telephones from remote locations. It presents a serious policy problem, as the CRTC has trouble rationalizing a double-standard for service provision in a competitive market. No one wants to establish and maintain payphones in remote locations because there is no profit to be made. Although, it may be unintentional, the policies of affordable access and competition are not always compatible.

Complicating the regulatory challenges of convergence is the structure of the CRTC itself, which bears the legacy of two independently regulated industries: broadcasting and telecommunications. The Telecommunications Act falls under the jurisdiction of the Industry Canada and is generally concerned with ownership, operation and competition in telecommunications. Although the Telecommunications Act requires 
telecommunication carriers in Canada to be majority owned and controlled by Canadians, the Act does not deal with content issues. Telecommunication carriers have always supplied the means to carry point-to-point communications and were not concerned by the actual content of those point-to-point communications. The Broadcasting Act, however, falls under the jurisdiction of Heritage Canada which deals specifically with communication content and ownership. Content regulations are primarily concerned with ensuring that Canadian-made content is both produced and distributed to a wide audience. The Canadian content regulations differentiate the Canadian system from the American system and are one of Canada's premier cultural policies.

The Broadcasting Act, now under the jurisdiction of the Department of Canadian Heritage, specifically refers to its cultural propositions in the prelude to the Act. Section 3 (b) reads:

the Canadian broadcasting system, operating primarily in the English and French languages and comprising public, private and community elements, makes use of radio frequencies that are public property and provides, through its programming, a public service essential to the maintenance and enhancement of national identity and cultural sovereignty...

It is clear, then, that broadcasting in Canada has a very real and substantial link to the development and maintenance of Canadian nationalism. In order to fulfill the objectives of the Broadcasting Act, broadcasting and broadcast distribution are very heavily regulated by the CRTC-the Canadian television market is very controlled. While the Telecommunications Act makes increased reliance on market forces one of its primary objectives (7f), the Broadcasting Act makes absolutely no commitment to 'market forces' and is quite clearly intended to mitigate the same forces. When technological convergence was emerging, the potential for conflict in communication policy circles 
became apparent. In 1995, CRTC Vice-Chairman Louis R. Sherman told the Symposium on National Convergence in Toronto that:

The content regulation that has traditionally been used as an instrument for protecting Canadian culture may be at odds with the increasing importance of open access to networks for all content providers; and it may not be sustainable in a more competitive domestic, and or, international free trade environment... the converging of technology places the Commission in a very interesting position. (CRTC-Sherman, 1995)

This was certainly one of the issues that the CRTC and the Information Highway Advisory Committee were to address. However, both bodies produced 'findings' which essentially stated that competition in communication distribution should be pursued, but that the government must ensure a place for Canadian culture on the Information Highway. Thus, little has changed since the flurry of activity in 1995 and the CRTC continues to administer virtually the same broadcasting and telecommunication policies. One policy tries to contain and manage the market, while the other tries to force competition into the market at great expense--and neither have been terribly successful.

\section{The Never Ending (Policy) Story}

As recently as 2003 , the CRTC continued to admit its struggles in trying to meet the policy objectives of each act. In its 2003 Report to the Governor in Council on the Status of Competition in Canadian Telecommunications, the CRTC explained that "local wireline competitors made little progress, as the incumbents continued to hold over 95\% of both local revenues and lines in $2002 "$ (3). Although there is generally robust competition in other areas, such as cellular and Internet provision, the primary focus and concern of the commission remains competition in facilities-based local service. One of the recent policy responses of Industry Canada has been to recommend the reduction or 
removal of foreign ownership restrictions for carriers in order to encourage growth through the development of new facilities. Among its suggestions in its April, 2003 report entitled Opening Canadian Telecommunications to the World, the parliamentary Standing Committee on Industry, Science and Technology also recommended a mandatory review of the Telecommunications Act every five years and that foreign ownership regulations be applied consistently to broadcast and telecommunication undertakings (Industry Canada 2003, xiii). The report specifically stated that the committee had not addressed issues of content, although it did address the issue of sovereignty, suggesting that most other countries, aside from Turkey, have more liberal foreign ownership restrictions than does Canada. Then Minister of Industry, Alan Rock, generally accepted the recommendations of the committee, while the broadcasting policy community was less than thrilled.

The Department of Canadian Heritage responded to Industry Canada's call by issuing a report from their own Standing Committee on Canadian Heritage in June, 2003 which contradicted the recommendation to remove foreign ownership restrictions. The following excerpt from the Department of Heritage's response to the report of its standing committee demonstrates the clear conflict of the two departments.

"... (the committee) registered its disagreement with the conclusions of the Standing Committee on Industry, Science and Technology which recommended the removal of restrictions for broadcasting distribution undertakings. ... The Standing Committee on Canadian Heritage recognized that present Canadian ownership requirements and the overall regulatory framework for broadcasting have helped overcome the major challenges Canada faces as a country with vast territory and a population one-tenth the size of the United States, the largest producer of programming in the world." (Department of Canadian Heritage $2003,10)$ 
Both Standing Committees clearly recognized the impact of convergence, but both were unwilling to provide any leeway in their respective jurisdictions to develop a consistent regulatory approach. As mentioned previously, the primary public policy concern of the Telecommunications Act is access, while the Broadcasting Act is entirely premised on regulating content. The Broadcasting Act, and the Department of Heritage make plane their intention to develop and fortify cultural sovereignty and national identity-claims which are virtually absent and all but flaccid in the Telecommunications Act.

So despite the present convergence of technologies in broadcasting and telecommunications, there remain two very different foundations for Canadian communication policies-neither of which has very effectively achieved its goals. Nor have they converged to produce a consistent approach to communication regulation in Canada. As evidenced by the reference to the United States in the preceding quote, the chief challenge of the broadcasting policy community is to manage the influence of the pop culture behemoth to the south. As referenced earlier, most communicative ventures of the Canadian government, including the telegraph and the railroad, were constructed in response to perceived threats from the south. Consequently, Canadian identity is deeply rooted in the systems that were established to mitigate the American influence. However, "nation building", in the grand sense, was a project of Central Canada and the federal government. As it was established in the historical introduction of this analysis, Saskatchewan developed its own unique methods to deliver the promises of communication technology quite independently from the federal government. Ultimately, communicative technologies are the foundation for both the province of Saskatchewan and the Canadian nation. However, the cultural ramifications implied by 
the Saskatchewan experience with communication technology are arguably different from the Canadian cultural attachment to communication technology.

\section{TECHNO-NATIONALISM-THE CULTURE OF COMMUNICATION}

Canadian communication scholar Maurice Charland has explored the cultural significance of the CPR in Canadian identity, suggesting that it has had a lasting impact on communication policy today. Charland uses the phrase 'technological nationalism' to describe this phenomenon. He writes:

Canada is valorized as a nation because it is the product of a technological achievement, and the railroad is the great product of heroic individuals who dreamt a nation... I perceive... a rhetoric of technological nationalism in anglophone Canada which ascribes to technolog' the capacity to create a nation by enhancing communication. $(1986,197)$

Charland argues that this cultural investment in technology has become a determining characteristic of the Canadian broadcasting system as well. He suggests that the CPR project was an effort by the state to legitimate its own existence through the creation of a nation. The CBC and the creation of a 'Canadian Broadcasting System' mark the continued effort of the state to construct a nation through connective technologies. However, Charland ultimately detests the 'absent nation' that technological nationalism has provided.

This vision of a nation is bankrupt, however, because it provides no substance or commonality for the polis except communication itself. As a consequence. technological nationalism's (Anglophone) Canada has no defense against the power and seduction of the American cultural industry or, indeed, of the technological experience. (198)

Although Charland speaks primarily of broadcasting in his analysis, the theoretical assertion that Canadian culture is absent is important to this study. If communication 
technology fails to provide a proper cultural foundation, then Saskatchewan is certainly the 'absent province' in the 'absent nation'.

Charland's analysis is heavily influenced by Harold Innis. Innis' historical economic analysis of Canadian development certainly pegs the advance of the West as a material supplier to the metropolitan centres of power in southern Ontario and Quebec. Of the CPR Innis writes that "the history of the Canadian Pacific Railroad is primarily the history of the spread of western civilization over the northern half of the North American continent." $(1971,287)$ Prior to the railroad's presence, there was little influence of the Canadian state in the vast North-West—only the commercial presence of the Hudson's Bay Company, fur traders, a handful of missionaries and the Metis. The railroad was, indeed, an extension of the state, the economy and the rule of law in one. It brought settlers, supplies and police-it permitted the rise of economy and state in the region. Thus, Saskatchewan, and the prairie region, exists as we know it because of technology. The possibility of a technological nationalism seems quite appropriate from the Saskatchewan perspective. The railroad was the economic foundation for the province and any distinctive cultural development follows from that technological birth. It could be said that what is common to prairie culture is the experience of technological mediation and deliverance itself.

The symbiosis of the telegraph and the railroad echoes Innis' notion that control of communication is fundamental to the maintenance and control of an empire. As Robert Babe states, "The telegraph speeded instructions from the east, while the Mounties ensured compliance in the west." (56) This centre-periphery relationship between the federal government and the prairies remains cemented in contemporary 
analyses of prairie politics. It was not only a political relationship, but an economic and communicative relationship as well. The technological foundations of the region, imposed by the design of the federal government, became cemented in prairie culture. Thus far, it appears that the communication technologies, the railroad and the telegraph, were mechanisms of capturing the West for the sake of the East and that all flows of traffic and communication suited the economic and political goals of the east. This may be true in large part. However, the introduction of the telephone certainly de-railed the total absence of local community.

\section{Calling Up Saskatchewan Culture}

It is clear that the railroad and the telegraph were primarily tools of commerce and the state structures that supported it. The railway moved primarily goods, while the telegraph carried information about goods, as well as administrative information and news. The telephone was a different technology in that it offered a relatively simple, accessible means of communication between individuals - for any sake at all. As telephones made their way west, they came into heavy use. The popularity and versatility of the technology, instead of sustaining the centre-periphery relationship, caused the first fractures between the prairies and central Canada. Dwayne Winseck writes:

As the telephone system was implemented in Canada cleavages opened up between business and residential customers; urban and rural areas; large and small communities; capital and labour; federal, provincial, and municipal governments; and corporate-sized versus independent providers of telephone service, etc. (TWU, 1988, pp. 2-5)... Canadians were among the world's heaviest users of the telephone, with some of the more sparsely populated prairie provinces, like Mamitoba and Saskatchewan, leading the world in the number of calls per telephone by a large margin. Socially, the telephone served as " $a$ great... factor in binding people together in scattered communities. " (1995) 
Robert Babe also suggests that the spread of the telephone caused more political upheaval than national unity. He goes further than Winseck by suggesting that the political struggles surrounding communication technology, dating back to the telegraph, are evidence that technological nationalism in communication policy is more myth than reality (1995). More important than the theoretical validity of the technological nationalism is the recognition that telephone usage differed on the prairies in some respects. Higher usage rates likely resulted from the needs and desires of a sparsely populated region that craved connection with each other and with the economic and political centres beyond the prairies.

At this time, it is important to recall the continued importance of the telegraph system. As mentioned previously, the federal government began regulating telegraph rates in 1910 because they provided the sole source of information for western newspapers. Dwayne Winseck roots his analysis of media convergence in the failure of the telegraph companies to maintain their vertical integration of content and carriage. $\mathrm{He}$ cites several examples to demonstrate that Canadian (and U.S.) courts initially recognized the futility of regulating voice communications, the telegraph and print independently and that they even recognized the telegraph providers as hybrid electronic publishers or common-carriers $(1998,339)$. Indeed, the principles of telegraphy bear a striking resemblance to the principles of digital communication. An original message, either voice, text or other, is encoded into a series of dots and dashes by an encoding machine which are transmitted electronically to another decoding machine which translates the electronic dots and dashes into the original message. In Winseck's view, "( $($ )elecommunications and publishing, thus, diverged because of monopolistic abuses, 
licensing practices, as well as government and regulatory decisions" $(1998,340)$. There was clearly no technical barrier to the early convergence of communication technology. The regulatory division of content from carriage clearly rested in other concerns.

As mentioned previously, the telephone had already begun taking hold of the general population as the telegraph companies fell from the fray. During the growth of the telephone, Canada also saw the growth of broadcasting — first through radio, followed by television. Again, Charland contends that the development of broadcasting in Canada followed from the technological nationalism founded in the CPR. Indeed, the first Canadian radio broadcasts were offered by the CNR. Charland writes:

State-supported radio, following the railroad's path, presented those who live in Anglophone Canada with an image of Canada. CNR sought to bind Canada with information just as rail had bound Canada economically. Thus was forged the link in the official Canadian mind between railroad, radio, and national identity. $(1986,203)$

This nation-building exercise through broadcasting runs strong through the history of Canadian broadcasting policy and is just as visible today as it was then. The distinction between the carriage of information and the precise content of communication became a central tenant of Canadian communication policy. The only communication policy considerations given to telephone regulation concerned access and price, not contentalthough the Criminal Code and other general acts of law certainly applied to telephone usage. Broadcasting policy, however, was almost exclusively concerned with the production and distribution of Canadian content. Charland suggests that because the Canadian culture was simply a culture of the communication technology itself, the 'Canadian content' was self-justification for the system. However, the focus must now shift on is the distinction between the regulation of carriage and content-the separation 
of communication technologies and their respective natures, as Saskatchewan presents a unique circumstance in common carriage.

The state's interest in broadcasting content subscribes to the notion that a Canadian identity could be fostered through proper Canadian content in broadcasting. However, this inception was not purely based on a Canadian ideal, but, as with the railroad, on pressure from the south. The first broadcasting signals to reach Canadians originated in the U.S. As the CPR was, in part, a response to the political and economic threat posed by the U.S., the broadcasting policy was partly a response to the American 'cultural threat' through broadcasting. This is a condition that continues to plague Canadian broadcasting policy today. Indeed, the majority of content (excluding advertising) on Canadian television always has been and continues to be U.S.

productions. U.S. content certainly drove the desire of Canadians who lived beyond the range of American broadcast signals to acquire those channels through large master antennas and networks of cable. This drove the development of cable television in Canada, while the federal government ensured that cable television providers failed to escape the scrutiny of carrying Canadian content. Broadcasting distribution remained heavily and separately regulated from telecommunications. In fact, no one firm could have its hand in both industries. The regulated divergence that began with the regulation of telegraph rates in 1910 remained the standard in Canada until the early 1990's, when the concept of technological convergence became en vogue in both industry and government. Digitization was the enabler that heralded the shift toward convergence once again and SaskTel, it will be argued, has pursued the most effective and meaningful path toward convergence, while current regulations may spoil those efforts. Ultimately, 
SaskTel is the last major communication carrier in Canada that maintains the public interest as its central tenet. However, many companies and agencies, including the CRTC, regularly employ the term 'public interest' in their policy justifications. It is important that we determine the precise nature of 'public interest' for the purpose of this analysis.

\section{DEFINING THE PUBLIC INTEREST}

Jurgen Habermas believed that the ideal democratic state rested upon a 'public sphere' in which rational debate over issues of importance was conducted. The centrality of communication in Habermas' conception of the public sphere is particularly suited to this analysis, as I will argue that SaskTel, has largely embodied the notion of providing a public sphere to Saskatchewan citizens through access to communication technology.

Firstly, the public sphere should be viewed as a domain where communication occurs. And such a thing as public opinion can only be formed through communication which is free from coercion. If opinions are forced or controlled by an other, they do not constitute an accurate or realistic public opinion. Secondly, everyone must have access to the public sphere in order for that domain to be accurately considered public. If access is denied, the 'public opinion' does not reflect the entire public. Finally, the state, as a coercive power, is the counterpart to, or the subject of, the public sphere. According to Habermas, the purpose of the public sphere is to exercise criticism and control over organized state authority. Thus, the conditions of the public sphere require universal access to un-coerced communication between individuals so that the public opinion can exercise some control over organized state authority. 
At this point a distinction must be drawn between the role of the state, which embodies 'public power', and the 'public sphere', which is largely independent from, and often in opposition to the state. Habermas writes that state power "...owes the attribute of publicness to its task of caring for the public, that is, providing for the common good of all legal consociates." (55) Thus, the state provides for the good of the public-it acts to serve the public interest. The public sphere, however, is the domain where citizens discuss affairs of general interest free from the authority of the state. That is why it can be said that the state is normally the subject of the public sphere; at least, it is the only subject of importance within the public sphere. Habermas conveniently adds the word political as a precursor to the term public sphere. The primary concern of the public sphere is to act as a control or check on the power of the state. Ultimately, a healthy public sphere, as it has been described, is a necessary condition of a healthy democracy. Erosion of the public sphere would interfere with the public's ability to criticize the state, thus leaving the power of the state un-checked. As communication is the life-blood of the public sphere, it is crucial that regulations concerning communication, which are developed and imposed by the state, must foster a healthy public sphere. This is the premise by which current communication policy in Canada must be evaluated.

If the ideal public sphere consists of a small village assembling to discuss the issues-a town-hall en perfect-there is no application for this concept in a large society like Canada. However, Habermas recognizes that "(w)hen the public is large, this kind of communication requires certain means of dissemination and influence; today, newspapers and periodicals, radio and television are the media of the public sphere." (55) Thus, the 'mass media' are attributed the task of mediating and maintaining the 
public sphere. Of course, 'mass media' is a term that encompasses several forms of communication, including all those forms listed by Habermas and, more recently, the Internet. His primary concern with the public sphere was that concentrated, private ownership of the means of communication has eroded the condition of the public sphere.

Therefore, there is a public concern in how forms of communication are controlled and, thus, there exists a public mandate for the state to exert some influence over forms of communication.

\section{SASKTEL, THE CULTURAL CARRIER}

The form of state influence evident in the SaskTel example is very different from the form of state influence in Maurice Charland's version of technological nationalism. The Saskatchewan government's interest was to provide access to communication services. Those services, in turn, enabled commercial growth, personal communication and entertainment all in one and all, arguably, in the public interest. Communication technology, including the railroad, gave rise to community interconnections through economic transactions and subsequent social interactions. Before those technologies, there was no 'public' to speak of in the province, let alone a public sphere. Common to the people of Saskatchewan is the experience of being delivered, mediated and supported by communication technologies. Certainly, cultural content comes from south of the border-despite the best efforts of Canadian communication policy to prevent it.

However, is the cultural production in Toronto, Montreal and Halifax any less foreign to the people of Saskatchewan? Charland may be correct in his contention that the culture of Canada is the culture of mediated communication, and Saskatchewan may be a strong 
example of this mediated culture. From the perspective of a Saskatchewan citizen, the culture of connective technology is based on economic and social necessity. Yet, the culture of curling, agriculture, rye whiskey, hockey, and community dances is no less real-communication technology has only enabled those interconnections. If there is a unique cultural trait in Saskatchewan, it is the strength of the public sphere as a result of the co-evolution of new people and new technologies in a harsh environment.

This analysis pits the nationalistic vision of Canada against the more local community of Saskatchewan (although both provincial borders and national borders are somewhat arbitrary in nature). This suggests a larger trend in the globalizing force of communication technology, as it both connects people within geographic communities while it also connects those communities to broader communities of a global scale. Nicholas Garnham raises this issue in his article The Mass Media, Cultural Identity, and the Public Sphere in the Modern World. Garnham suggests that because communication technology is, in part, responsible for driving globalization, it will affect the public sphere and, consequently, democracy as the nation state begins to fade (1993). It is, indeed, necessary for individuals in a given community to feel that political accountability rests somewhere-preferably in their chosen institutions of governance. In the case of Canada, Charland seems to suggest that the Canadian government has strained to assert its own legitimacy over a vast and disparate landscape through the use of communication technology and a nationalizing discourse of technology. Thus, the very technologies upon which the Canadian state attempted to justify its legitimacy have also served to undermine it. It is more ironic, still, to recognize that the settlement of the prairies, which was partly a Canadian response to the American threat, has now come to embrace 
elements of American culture and loathe the political powers in Ottawa. If the culture of Saskatchewan is independent of the nationalizing effort, perhaps Saskatchewan citizens also consider that political accountability rests within their own community, within their public sphere.

Communication scholar David Young suggests that the discourses of technological nationalism and technological determinism both point to “...struggles between dominant and subordinate agents" $(2003,211)$ This, is perhaps, the best way to frame the communication policy shift toward re-convergence and competition.

Saskatchewan has done well for its citizens through cross-subsidization, convergence and crown ownership of communication technology for the past 80 years. The Canadian government has continued to flip-flop on the issues of convergence and ownership for the past 100 years. The most recent shift toward a market-driven policy has required, perhaps, more regulatory intervention than ever before in order to carve out room for competitors while maintaining a dated cultural policy that supports the economic interests of Canadian advertisers much more than a nationalizing discourse. As a part of this shift, communication carriers will no longer enjoy geographic monopolies and they will no longer be permitted to cross-subsidize services through averaged rates. As it has always been the case, the dominant agent in this battle-the Canadian government-is forcing SaskTel, the subordinate player, to surrender the foundations of its century-old success. Is this still the exercise of nation building? 


\section{CONCLUSION}

If Canadian communication policy continues down its current path, it will force SaskTel to compromise its historical regard for fair and reasonable access to quality communication services through cross-subsidization of services throughout the province. This, in turn, could impact the economic and cultural foundations of the province, causing a withering of the Saskatchewan public sphere—a place, where there arguably rests more political legitimacy than there does in the Canadian state. Instead, SaskTel must be permitted, as the common communication carrier, to continue to link Saskatchewan citizens through innovative communication technologies. Saskatchewan has met its own needs and fostered its own technologically mediated culture for the past hundred years. For the 'absent' culture of Saskatchewan to continue, it, ironically, requires the 'absence' or relaxing of federal regulation.

In federal regulation, Canadian nationalism has sought to create itself through connective technologies which have, in fact, served to destroy their very intention. Saskatchewan has both embraced those technologies and made them their own through independent development and resistance to the control and influence of the federal government. Secondly, the continued state ownership of SaskTel has ensured the absence of foreign (both extra-provincial and international) economic pressure that could impede the true designs and desires of the Saskatchewan people. Finally, the pursuit of a common carrier model has ensured the technological supremacy of the system and that cultural ambitions are not rooted or enshrined in the technology of communication itself. Rather, the connective technologies serve as infrastructural improvements akin to roads, railroads and grain elevators. Early communication technology, like party lines and 
municipal systems, in fact, served only local communities in Saskatchewan-much like the Wheat Pool and Co-operatives were locally developed solutions for economic problems. Although the Saskatchewan identity may be strongly related to connective technologies, the continued uniqueness of the provincial communication system in its technological achievement, its political position and its place in the Canadian marketplace indicate that the effect and influence of communication technology is distinct from other regions in the country.

SaskTel currently continues to espouse its official vision that "SaskTel is a highly innovative and competitive communications solutions provider for our Customers worldwide, delivering sound financial returns and public policy benefits to the people of Saskatchewan." Public policy benefits remain the cornerstone of SaskTel's current efforts and drive its distinctiveness. How long they can maintain that position is extremely uncertain in the face of regulatory, political and financial pressures as they have been described in this analysis. However, the unique history of communication in Saskatchewan will remain a critical component of its cultural identity. Perhaps, there is truly a unique culture in Saskatchewan that has, indeed, been enabled by connective technologies-which would be a sad irony for the grand designers of Canadian nationalism. Communication technology has neither enabled an American, nor a Canadian identity in Saskatchewan, but an independent one. SaskTel simply remains a political and practical expression of that identity. 
1882 First known two-way voice conversation in Saskatchewan took place in Regina.

1882 First telephone exchange in SK al South Railway near Hamilton

1903

1905 About 2000 telephones in operation in Saskatchewan when it became a province.

1906

Bell Connection from Winnipeg to Regina to provide first long distance service.

Francis Dagger, appointed by Scott to investigate the telephone

1908 situation in the province, reported his findings to the legislature which began the process of nationalization.

1909

1911

1917

1921

1923 The government telephone service uses lines to transmitt the first broadcast church service in Canada.

1927

1929

1930

1932

1934

1936

1944

1946

1947 SGT is established on June 1
The Telephone Acts, assented to on June 12 - permitted the

newly formed department or raitway, telegraph and

The Board of Railway Commissioners granted

Walter Scott is first Premier of a Liberal govemment until 1916.

Raitway Act passed.

Laurier is PM of a Liberal government until 1911.

Saskatchewan becomes province.

telephones to build and operale systerns. Municipalities

jurisdiction over telegraph transmission rates. were encourage to buid

SK gov't purchases all privale long distance holdings and facilities

\section{Borden elected PM of Conservative/Unionis govemment until 1920 \\ Drayton-Ackworth Commission on Raitways reported in May 1917, recommending nationalization. \\ Mackenzie King elected PM of a Liberal government until 1930}

CNR begins radio broadcasting.

Radio Telegraph Act establishes Federal Radio Commission

JTM Anderson is elected Premier of a Co-operative government until 1934.

January 25th, the Official Opening of the Trans-Canada Telephone Systern from Halifax to Vancouver.

Retum of Liberal Gov't under James G. Gardner and William

J. Patterson until 1944

T. C. Douglas elected Premier of CCF government until

1961.

Saskatchewan Government Insurance Office is eslablished.

Saskatchewan Transportation Company is founded.

Saskatchewan Government Airways established to fly

miners, prospectors, elc. between northern locations. The

department also operaled several radio telephone sels.

(Archer, 272)

Government Finance Office (GFO) established to hoid and

manage crown investments.
Aird Commission on Radio Broadcasting recommends setting up a national broadcaster.

Bennett elected until 1935.

Broadcasting Act creates Canadian Radio Broadcasting Commission.

Creation of Canadian Broadcasting Corporation. 
952

1955

1961

1963

1964

1965

1968

1969

1971

1972

1973

1978 COLD WAR - effect on telecom infrastructure?

SGT establishes service in Uranium City.

SGT completes its section of the Trans Canada micro-wave

1957 network which was used for both broadcasting and

telecommunicalions.

1959 First mobile "car phone" is introduced.

SGT became Saskatchewan Telecommunications and adopted

the trade name SaskTel.

1976 Sask Tel granted permission by the CRTC to become a common carrier for television signals in SK.

1979 SaskTel installed the first digital switching system in the province at La Ronge.

1980 SaskTel begins the installation of fiber-optic cable, which, when completed in 1984 was the world's largest fiber-optic network.
Saskatchewan Hospitalization Plan was introduced on January 1.

Saskatchewan Power Commission is Established. COLDWAR

\section{Woodrow S. Lloyd elected Premier and replacement CCF leader until 1964.}

W. Ross Thatcher elected Premier of a Liberal government until 1971

Allan E. Blakeney elected Premier of an NDP government until 1982.

SaskOil is established to explore for, mine, refine and sell crude.

Hall Commission - grain transportation in Western Canada (raiilways). GFO changed to Crown investments Corporation.
St. Laurent elected until 1957

Massey Commission

CBC Television is launched

Diefenbaker elected until 1963

O'Leary Commission on publications

Pearson elected until 1968

Fowler Commission on Broadcasting

Trudeau becomes PM

New Broadcasting ActCRTC developed.

Telesal Canada is incorporated as an Act of

Parliament.

Canadian Content is introduced to broadcasting industry.

Anik $A 1$ is launched as the world's first

commercial, domestic communications satellite in geostationary orbit.

CBC begins broadcasting on Telesat

CRTC takes over regulatory jurisdiction for both broadcasting and telecommunications from the CTC

Teledon project is introduced.

Department of Communications is established

Grant Devine is Elected. Saskalchewan Public Utilities

Review Commission is established to set rates for the three large crowns (SaskTel, SaskPower and SGI).

Mulroney takes power until 1993

Government selis Saskoil

SaskTel International was launched; Sells off its cable distribution network in SK. 
SaskTel International invests in LCL Cable in the U.K. to develop TV and voice-line network.

SaskTel negotiates a five-year moratorium on the introduction of long-distance competition and regulation by the CRTC.

1993 SaskTel launched "Hollywood al Home" VOD Irial in Regina.

9996 SaskTel is the first ISP in Canada to offer broadband over ADSL.

Crown Investmenis Review by the Provincial Government.

SaskTel changed its $35 \%$ stake in Satum Communications, for an equity share in Austar Communications.

1999 SaskTel and CRTC form a plan to bring SaskTel under foderal regulations.

SaskTel falls under the regulalory jurisdiction of the CRTC on

2000 June 30

2001 March 12, CRTC approves BDU license lor SaskTel.

2002 September 12, Launch of SaskTel Max service.

rederal regulations.
Government passes new Broadcasting Act on June 4.

The CRTC introduces long-distance

competition. Government selis its interest in Telesat to Alouette Telecommunications Inc. Government passes new Telecommunicalions

Act on October 25.

Chretien comes to power

CRTC 94-14 provides new regulatory

ramework for telecommunicalions that

emphasizes markel forces. Federal

government (industry) instructs the CRTC to

compile a report on the state of digital

communications and design a new regulatory framework.

Competition and Culture on Canada's

Information Highway is released (dubbed the

Convergence Report). It calls for competition in

all sectors of communication carriage.

CRTC $1997-25$ permils competition in

broadcast carriage. 


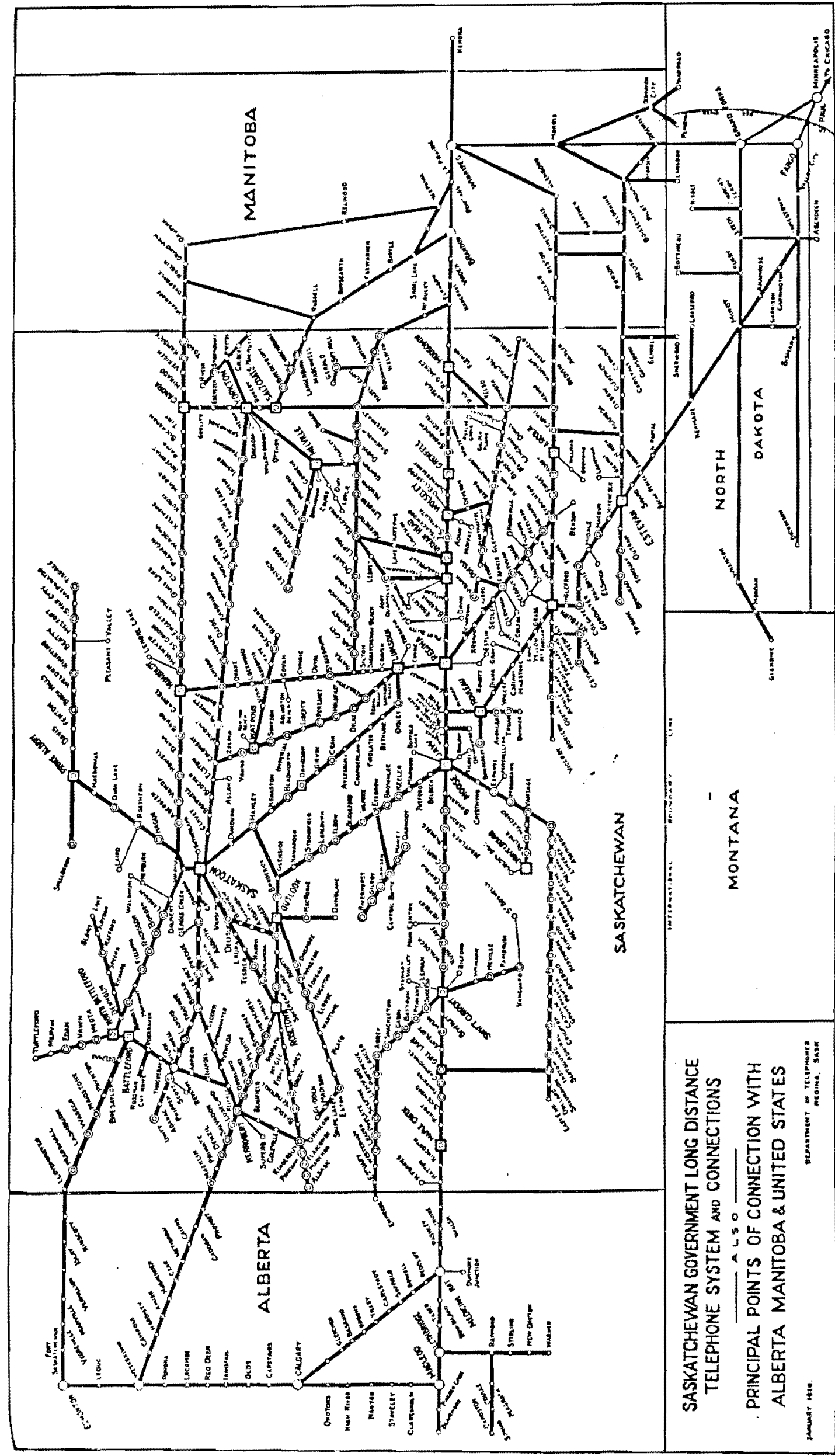




\section{Works Cited}

Archer, John H. Saskatchewan A History. Saskatoon: Western Producer Prairie Books, 1980.

Babe, Robert E. Telecommunications in Canada: Technology, Industry and Government. Toronto: University of Toronto Press, 1993.

Board of Highway Commissioners. Report for the Fiscal Year Ended April 30, 1914. J. A. Calder. Regina: 1914.

Canada. A Broadcasting Policy for Canada: A Report of the Standing Committee on Communication and Culture, Queen's Printer, 1988.

Canada. Competition and Culture on Canada's Information Highway: Managing the Realities of Transition. CRTC, May 19, 1995.

Canada. Order in Council P.C. 1994-1689.

Canada. Broadcasting Act, 1991. Statutes of Canada Chatper B-9.01, 1991

Canada. Report of the Task Force on Broadcasting Policy. Gerald Lewis \& Florian Sauvageau. Minister of Supply and Services, 1986.

Canada. Telecommunications Act. Statutes of Canada Chapter 38, 1993.

Canadian Radio-television and Telecommunications Commission. Decisions CRTC 76432, 76-433, 76-434, 76-435, 76-436, 76-437. Ottawa: CRTC Notices and Decisions, 1976, 1977. 153-163.

Canadian Radio-television and Telecommunications Commission. Report CRTC 102-5. Ottawa: 1976. 241-42.

Canadian Radio-television and Telecommunications Commission. Decision CRTC 7785. Ottawa: CRTC Notices and Decisions 1977, 1978. 344-346.

Canadian Radio-television and Telecommunications Commission. Decision CRTC 7893. Ottawa: CRTC Notices and Decisions 1978, 1979. 603-604.

Canadian Radio-television and Telecommunications Commission Decisions and Notices Accessed at www.crtc.ca: Telecom Decision CRTC 92-12. Telecom Decision CRTC 94-19. Telecom Decision CRTC 97-8. 
Telecom Decision CRTC 2001-171.

Telecom Decision CRTC 2002-4.

Telecom Decisions CRTC 2002-34.

Telecom Public Notice 2004-1; includes links to British Columbia Public Interest Advocacy Centre (BCPIAC) and Call-Net Submissions.

Telecom Decision CRTC 2004-2.

Canadian Radio-television and Telecommunications Commission. Report to the Governor in Council on Status of Competition in Canadian Telecommunication Markets. Ottawa: November, 2003.

Charland, Maurice. "Technological Nationalism." Canadian Journal of Political and Social Theory. Vol X, No 1-2, 1986. p. 196-220.

Ching, Donald for SaskTel. Letter to Hon. Lucienne Robillard and Hon. Ralph Goodale. SaskTel Regulatory Affairs Department Archives, April 26, 2004.

Cohnstaedt, Wilhelm. Western Canada 1909: Travel Letters by Wilhelm Cohnstaedt. Trans. H. Holle-Scherer, Ed. K. H. Burmeister. Regina: Canadian Plains Research Center, 1976.

Dagger, Francis. Report with Respect to the Development of the Telephone Service in the Province of Saskatchewan. Department of Railways, Regina: 1908.

Dalfen, Roger for CRTC. Sustaining Distinctiveness: The role of television in Canada. Speech to $25^{\text {th }}$ Banff Television Festival. Banff: June 14, 2004

Department of Canadian Heritage. Our Cultural Sovereignty: Report of the Standing Committee on Canadian Heritage. Ottawa: June 2003.

Department of Public Works. Report of the Superintendent of Highways on Highway Improvement for 1907. A. J. McPherson. Regina: 1907.

Department of Railways, Telegraphs and Telephones. Annual Report, March 1, 1910. Hon. J. A. Calder, Commissioner. Regina: 1910.

Department of Railways. Anmual Report for the Financial Year Ended February 28 , 1913. J. A. Calder. Regina: 1913.

Department of Railways. Anmual Report, year ended April $30^{\text {th }}$ 1914. J. A. Calder. Regina: 1914.

Department of Telephones. Annual Report for 1933. James Fraser Bryant. Regina: Oct. $17,1933$. 
Department of Telephones. Anmal Report for 1934. James Fraser Bryant. Regina: June $30,1934$.

Dominion Bond Rating Service. Credit Rating Report on Saskatchewan Telecommunications Holding Corporation. June 18, 2004.

"Editorial." The Leaderpost. Regina: November 4, 2003, A8.

Fraser, Matthew. Free-for-All: The Struggle for Dominance on the Digital Frontier. Toronto: Stoddart Publishing Co. Limited, 1999.

Habermas, Jurgen. "The Public Sphere." Media Studies: A Reader, $2^{\text {nd }}$ Edition. Ed. Paul Marris \& Sue Thornham. New York: New York University Press, 2000. 92-97.

Howe, Eric. Public versus private investment in Saskatchewan. Interview on CBC Radio One. Regina, Saskatchewan: 12:55pm, October 27, 2003.

Garnham, Nicholas. The Mass Media, Cultural Identity, and the Public Sphere in the Modern World. 1993.

Industry Canada. Building the Information Society: Moving Canada into the 21st Century. Information Highway Advisory Council, 1996.

Industry Canada. Ensuring a Strong Canadian Presence on the Information Highway. Canadian Content and Culture Working Group of Information Highway Advisory Council, 1995.

Industry Canada. Opening Canadian Telecommunications to the World: Report of the Standing Committee on Industry, Science and Technology. Ottawa: April 2003.

Love, Ronald S. Dreaming Big: A History of SaskTel. Regina: SaskTel-PrintWest, 2003.

Macdonald, J.S. “The Dominion Telegraph," Canadian North-West Historical Society Publications: Chapters in the North-West History Prior to 1890 -- Related by Old Timers. Battleford, 1930: Vol.I No.VI.

Pitts, Gordon. Kings of Convergence: The Fight for Control of Canada's Media. Canada: Doubleday Canada, 2002.

Sabia, Michael J. Remarks to the Quebec City Chamber of Commerce. Speech for BCE Inc. Quebec City, April 27, 2004.

Saskatchewan. An Act Respecting the Department of Railways, Telegraphs and Telephones; An Act Respecting Municipal Telephone Systems; An Act Respecting Rural Telephone Systems. Regina: Statutes of Saskatchewan Chapter 5, 1908. 
Saskatchewan Telecommunications (SaskTel). Anmual Reports for 1976, 1980, 1981, 1991, 1992, 1994, 1995. Regina: Queen's Printer.

“SaskTel's Loss Slammed." StarPhoenix. Saskatoon: April 8.2004, A4.

Sherman, Louis R. for CRTC. Convergence and Regulation. Speech for Symposium on National Convergence. Toronto: February 7, 1995.

"What they said: Crowns the focus once again." The Leaderpost. Regina: October 28, 2003, A8.

Winseck, Dwayne. "A Social History of Canadian Telecommunications." Canadian Journal of Communications. Vol 20, No 2, 1995.

Winseck, Dwayne. "Pursuing the Holy Grail: Information Highways and Media Reconvergence in Britain and Canada." European Journal of Communication. Vol 13, No 3, 1998. p. 337-374.

Young, David. "Discourses on Communication Technologies in Canadian and European Broadcasting Policy Debates." European Journal of Communication. Vol. 18, No 2 , 2003. p. 209-242. 